\title{
Development of Odor Hedonics: Experience-Dependent Ontogeny of Circuits Supporting Maternal and Predator Odor Responses in Rats
}

\author{
Rosemarie E. Perry, ${ }^{1,2,3}$ Syrina Al Aïn, ${ }^{1,2}$ Charlis Raineki, ${ }^{1,2}$ Regina M. Sullivan, ${ }^{1,2}$ and Donald A. Wilson ${ }^{1,2}$ \\ ${ }^{1}$ Emotional Brain Institute, Nathan Kline Institute for Psychiatric Research, Orangeburg, New York 10962, 2Department of Child and Adolescent Psychiatry, \\ New York University Langone Medical School, New York, New York 10016, and 32Department of Neuroscience and Physiology, Sackler Institute, New York \\ University School of Medicine, New York, New York 10016
}

A major component of perception is hedonic valence: perceiving stimuli as pleasant or unpleasant. Here, we used early olfactory experiences that shape odor preferences and aversions to explore developmental plasticity in circuits mediating odor hedonics. We used 2-deoxyglucose autoradiographic mapping of neural activity to identify circuits differentially activated by biologically relevant preferred and avoided odors across rat development. We then further probed this system by increasing or decreasing hedonic value. Using both region of interest and functional connectivity analyses, we identified regions within primary olfactory, amygdala/hippocampal, and prefrontal cortical networks that were activated differentially by maternal and male odors. Although some activated regions remained stable across development (postnatal days 7-23), there was a developmental emergence of others that resulted in an age-dependent elaboration of hedonic-response-specific circuitry despite stable behavioral responses (approach/avoidance) to the odors across age. Hedonic responses to these biologically important odors were modified through diet suppression of the maternal odor and co-rearing with a male. This allowed assessment of hedonic circuits in isolation of the specific odor quality and/or intensity. Early experience significantly modified odor-evoked circuitry in an age-dependent manner. For example, co-rearing with a male, which induced pup attraction to male odor, reduced activity in amygdala regions normally activated by the unfamiliar avoided male odor, making this region more consistent with maternal odor. Understanding the development of odor hedonics, particularly within the context of altered early life experience, provides insight into the development of sensory processes, food preferences, and the formation of social affiliations, among other behaviors.

Key words: development; hedonics; maternal odor; olfaction; predator odor; smell

Significance Statement

Odor hedonic valence controls approach-avoidance behaviors, but also modulates ongoing behaviors ranging from food preferences and social affiliation with the caregiver to avoidance of predator odors. Experiences can shape hedonic valence. This study explored brain circuitry involved in odor hedonic encoding throughout development using maternal and predator odors and assessed the effects of early life experience on odor hedonic encoding by increasing/decreasing the hedonic value of these odors. Understanding the role of changing brain circuitry during development and its impact on behavioral function is critical for understanding sensory processing across development. These data converge with exciting literature on the brain's hedonic network and highlight the significant role of early life experience in shaping the neural networks of highly biologically relevant stimuli.

\section{Introduction}

Sensory systems must detect and discriminate stimuli, but also play a role in attaching meaning to the stimulus to evoke appropriate approach/avoidance responses. This may be particularly true in the olfactory system, which is heavily and reciprocally connected to limbic structures such as the amygdala, orbitofrontal cortex (OFC), and hippocampus in humans and other mammals. In fact, activity of second-order neurons in the olfactory

\footnotetext{
Received Feb. 26, 2016; revised April 30, 2016; accepted May 9, 2016.

Author contributions: R.E.P., R.M.S., and D.A.W. designed research; R.E.P., S.A.A., and C.R. performed research; R.E.P., R.M.S., and D.A.W. analyzed data; R.E.P., R.M.S., and D.A.W. wrote the paper.

This work was supported by the National Institutes of Health (Grants DCO09910, DCO03906, MH091451, and HD083217 and Grant T32MH096331 to R.E.P.).

The authors declare no competing financial interests.
}

Correspondence should be addressed to either Rosemarie Perry or Donald Wilson, Emotional Brain Institute, Nathan Kline Institute for Psychiatric Research, 140 Old Orangeburg Road, Orangeburg, NY 10962, E-mail: rosemarie.perry@nyumc.org or donald.wilson@nyumc.org.

DOl:10.1523/JNEUROSCI.0632-16.2016

Copyright $\odot 2016$ the authors $\quad 0270-6474 / 16 / 366634-17 \$ 15.00 / 0$ 
bulb (OB) convey information about learned (Wilson et al., 1987; Kass et al., 2013; Dias and Ressler, 2014; Morrison et al., 2015) or state-dependent (Pager, 1986) hedonic valence of odors and even innately aversive odors evoke unique olfactory system activity (Vanderwolf et al., 2002; Khan et al., 2007; Kobayakawa et al., 2007; Lowry and Kay, 2007; Root et al., 2014). Furthermore, learned aversive and appetitive odors differentially activate rat anterior (aPCX) and posterior ( $\mathrm{pPCX}$ ) piriform cortex (Moriceau and Sullivan, 2004b; Moriceau et al., 2006; Xia et al., 2015) and human PCX (Gottfried et al., 2002; Li et al., 2006). These hedonically modulated responses within the primary sensory pathway may reflect either intrinsic coding properties of olfactory pathway neurons for appetitive and aversive odors and/or interaction between the sensory pathway and limbic circuits (Sadrian and Wilson, 2015). For example, in addition to primary sensory areas, odors varying in hedonic valence are differentially encoded by activity within the amygdala, OFC, and other regions (Schoenbaum et al., 1999; Anderson et al., 2003; Gottfried, 2007; Root et al., 2014; Jin et al., 2015; Patin and Pause, 2015). Convergence of olfactory pathway and limbic circuits could therefore help tag odor hedonics to the representation of the odor itself. Odor hedonics are a major factor in varied functions such as food preferences and social affiliations (Doty, 1986).

Life-long odor preferences and aversions are often shaped by early developmental experience (Mennella and Beauchamp, 1997; Doty, 2003; Herz et al., 2004; Mennella et al., 2004; Rinck et al., 2011; Sullivan et al., 2011). The olfactory system has an early functional development, playing an important role in mammalian infant approach to the mother in humans and nonhumans (Sullivan and Toubas, 1998; Raineki et al., 2010c; Schaal, 2014). Odor learning during the perinatal period can induce odor preferences and aversions that shape odor-guided behavior throughout life (Fillion and Blass, 1986; Mennella et al., 2004; Sevelinges et al., 2007), in part by modifying odor processing within OB and cortex (Johnson et al., 1996; Sevelinges et al., 2011; RinconCortes et al., 2015). However, the olfactory system does not function in isolation of other brain regions and has extensive reciprocal connections with circuits involved in emotion and memory (Gottfried, 2006; Martinez-Marcos, 2009). This larger network within which the olfactory system functions can show a much more extended developmental emergence (Cunningham et al., 2002; Fuster, 2002), which could shape the expression and neural underpinnings of odor hedonics.

Here, we explored the ontogeny of behavioral and neural network responses to biologically relevant odors (maternal odor and male odor) from birth to weaning in rats. Maternal odor induces attraction at all of these ages, although the attraction weakens in some aspects as pups approach weaning. In contrast, male odor in pups raised exclusively with the mother is highly aversive to pups. We used 2-deoyxglucose (2-DG) metabolic mapping to identify neural circuit components and their functional connectivity activated in response to these hedonically different odors at different ages. We found that, although network membership changed with development, core circuits differentially active during preferred and avoided odors were present across early development. In addition, we modified the hedonic valence of these same odors through early experience (e.g., suppression of maternal odor, co-rearing with the male) and performed the same neural mapping analyses. This allowed us to identify circuits selective for preferred or aversive odors in isolation of the actual identity of the odor. Our results demonstrate how odor hedonicvalence-specific neural circuits emerge and elaborate during early development to allow appropriate odor-guided behavior during a time of dramatic changes in an animal's ecological niche.

\section{Materials and Methods}

Subjects

Male and female Long-Evans rats born and bred in our colony (originally from Harlan Laboratories) were used as subjects at postnatal days 7 (PN7), PN14, and PN23 ( $\pm 1 \mathrm{~d}$ ). They were housed with their mothers in polypropylene cages $(34 \times 29 \times 17 \mathrm{~cm})$ with ample wood shavings for nest building in a $20 \pm 1^{\circ} \mathrm{C}$ environment on a $12 \mathrm{~h}$ light/dark cycle. Day of birth was considered PN, and litters were culled to 12 pups ( 6 males, 6 females) on PN1. Food and water were available ad libitum. All subjects were used only one time and all procedures were approved by the Institutional Animal Care and Use Committee in accordance with guidelines from the National Institutes of Health. A total of 372 males and 372 females were used, with equal numbers of males and females assigned to each group.

\section{Early life experience}

Control. Litters were housed with their mothers in polypropylene cages $(34 \times 29 \times 17 \mathrm{~cm})$ with ample wood shavings for nest building. Mothers were fed normal rat chow (Purina LabDiet \#5001).

Maternal odor suppression. Maternal odor was suppressed via administration of a sucrose-based, fat-sufficient diet (Harlan Teklad \#TD.69446), which blocks the caecotrophe production that is dominant in maternal odor (Leon, 1975). Because maternal odor is learned by pups, this procedure provides us with the ability to test the hedonics of maternal odor in pups that have not learned the natural maternal odor (Teicher and Blass, 1977; Sullivan et al., 1990; Hofer, 1994).

Familiar male odor. Litters were reared as described above, but were housed with both their mothers and fathers in polypropylene cages $(48 \times$ $34 \times 20 \mathrm{~cm}$ ) and fed normal rat chow. This procedure blocks the emergence of threat to male odor at PN10 and provides a method with which to assess the neural basis of the hedonics of male odor without activation of the threat system (Mennella and Moltz, 1988).

\section{Behavioral testing}

$Y$-maze testing of approach/avoidance. Pups were placed in a start box $(10 \times 8.5 \times 8 \mathrm{~cm}$ for PN8 and PN14; $19 \times 10 \times 10 \mathrm{~cm}$ for PN23 $)$ and given 5 trials to choose between 2 arms $(24 \times 8.5 \times 8 \mathrm{~cm}$ for PN8 and 14; $29 \times 109.5 \mathrm{~cm}$ for PN23) separated by 2 sliding doors, with $1 \mathrm{arm}$ containing the experimental odor and the other arm containing a control odor. For biological odors (maternal and male odor), the experimental odor was delivered via a flow dilution olfactometer and the control odor was a familiar odor of clean wood shavings $(20 \mathrm{ml}$ in a Petri dish). For artificial odors (2-phenylethanol, acetophenone, amyl acetate, ethyl buterate, eugenol, guaiacol, heptanal, hexanoic acid; Sigma-Aldrich), $20 \mu \mathrm{l}$ of the experimental odor (saturated or diluted with mineral oil to 10 parts per million (PPM) was placed on a KimWipe and the control odor was $20 \mu \mathrm{l}$ of mineral oil on a KimWipe. These odorants were chosen based on odor preference data published by Khan et al. (2007) and Mandairon et al. (2009). For each trial, the pup was given 1 min to make a choice. It was considered a choice when the pup's entire body entered the alleyway of an arm (Sullivan and Wilson, 1991; Moriceau et al., 2009; Raineki et al., 2010a; Raineki et al., 2015).

Odor presentations. After a 10 min acclimation period, 11 experimental odor presentations were delivered via a flow dilution olfactometer controlled by Ethovision software $(2 \mathrm{~L} / \mathrm{min}$ flow rate, 1:10 odor: air, $4 \mathrm{~min}$ intertrial interval) into beakers containing one pup each $(600 \mathrm{ml}$ beakers for PN7-9, $2000 \mathrm{ml}$ beakers for PN13-15 and PN23-25). The two biological odors used were maternal odor and male odor. A "no odor" control group sat undisturbed for the same duration but, instead of receiving an odor stimulus, received a clean air stream. For maternal odor, two anesthetized mothers were placed in an airtight chamber connected to a flow dilution olfactometer (Raineki et al., 2015). Maternal odor is diet-dependent, so pups will approach any lactating mother on the same diet as their own mother (Leon, 1975, 1980; Sullivan et al., 1990). For male odor, an awake male was placed in an airtight chamber connected to a flow dilution olfactometer. In the case of familiar male 
odor, a father (housed in the same colony on same diet as the test litters' fathers) was placed into the olfactometer.

Activity score. Individual activity levels during odor presentations were scored using automated-tracking with Ethovision software (Noldus).

Nipple attachment test. Before testing, a mother was anesthetized with urethane to prevent milk letdown. The natural maternal odor was eliminated from the mother's ventrum for this test and reintroduced via an airstream infused throughout the testing environment from underneath a screen mesh floor supporting the mother and pup. This procedure induces nipple attachment onto a mother with maternal odor removed and indicates that the odor does not have to be on the mother's ventrum to induce pup nipple attachment (Raineki et al., 2010a). The ventrum of the mother was washed with acetone, alcohol, and then water, to remove the maternal odor (Hofer et al., 1976; Teicher and Blass, 1977). The washed mother was placed on her side in a testing chamber $(25 \times$ $40 \times 20 \mathrm{~cm}$ ) to provide the pups with access to the nipples. The pup was then placed on the opposite side of the chamber. Latency to nipple attach was recorded throughout the 3 min test. We have used this procedure in previous studies (Raineki et al., 2010a; Sarro et al., 2014; Rincon-Cortes et al., 2015).

The rationale for this test is that pups require maternal odor to nipple attach; without maternal odor, nipple attachment does not occur (Hofer et al., 1976; Teicher and Blass, 1977). Maternal odor is learned and raising pups without exposure to the natural maternal odor removes this odor's ability to support nipple attachment (the suppressed maternal odor group). These pups do nipple attach, but now rely on their mother's new maternal odor, which is not dependent upon gut bacteria and is sufficient to produce the OB changes induced by natural maternal odor in typically reared pups (Sullivan et al., 1990). Therefore, in this test, pups raised with a mother fed a diet that suppressed the natural maternal odor would be expected to fail to nipple attach to a naturally odorized mother or a washed mother with natural maternal odor infused in the air surrounding the pup (Sullivan et al., 1990).

\section{2-DG autoradiography}

Pups were injected with ${ }^{14} \mathrm{C}$ 2-DG $(20 \mu \mathrm{Ci} / 100$ g, s.c. $) 5 \mathrm{~min}$ before odor presentations and brains were removed $45 \mathrm{~min}$ later at the end of odor presentations. Brains were stored in a $-80^{\circ} \mathrm{C}$ freezer before being sectioned in a cryostat $(20 \mu \mathrm{m})$ at $-20^{\circ} \mathrm{C}$. Every other section was collected onto a coverslip and exposed to x-ray film (Kodak) for $5 \mathrm{~d}$ with ${ }^{14} \mathrm{C}$ standards $(10 \times 0.02 \mathrm{mCi}$; American Radiolabeled Chemicals; Coopersmith et al., 1986; Sullivan and Wilson, 1995). Regions of interest (ROIs) were analyzed using ImageJ software, a computer-based system for quantitative optical densitometry. For computing 2-DG uptake, autoradiographic density was measured in both hemispheres of the brain for each ROI (described below) and then averaged across both hemispheres. 2-DG uptake was expressed relative to 2-DG uptake in the corpus callosum (or relative to the periventricular zone in the case of the $\mathrm{OB}$ ) to control for differences in exposure levels or section thickness (Sullivan et al., 2000). Four brain slices per ROI were analyzed per animal and the reported results reflect an average of relative 2-DG uptake across all four slices. An increase in autoradiographic density indicates increased neural activation, but does not differentiate between inhibitory and excitatory activity. All analyses were conducted by investigators blinded to the experimental conditions. We have used this procedure frequently in previous studies (Sullivan and Wilson, 1995; Landers and Sullivan, 1999; Sullivan et al., 2000; Moriceau et al., 2009; Boulanger Bertolus et al., 2014; Debiec and Sullivan, 2014).

$O B .2-D G$ uptake was measured using ImageJ software within odorspecific glomeruli ("hot spots"), as well as within the periventricular zone of the OB, as described previously (Sullivan and Wilson, 1995; Sullivan et al., 2000; Moriceau et al., 2009). Odors produce odor-specific patterns of 2-DG uptake in the glomerular layer of the OB (Lancet et al., 1982; Xu et al., 2000; Johnson and Leon, 2007). Glomerular "hot spots" were identified by visually scanning the entire $\mathrm{OB}$ for the presence of odor-specific glomerular foci, which are generally two to three times above background glomerular layer uptake and thus are easily observed (Fig. 1; Sullivan and Wilson, 1995). No staining was required for the analysis of the OB because anatomical landmarks are visible with 2-DG (Fig. 1).
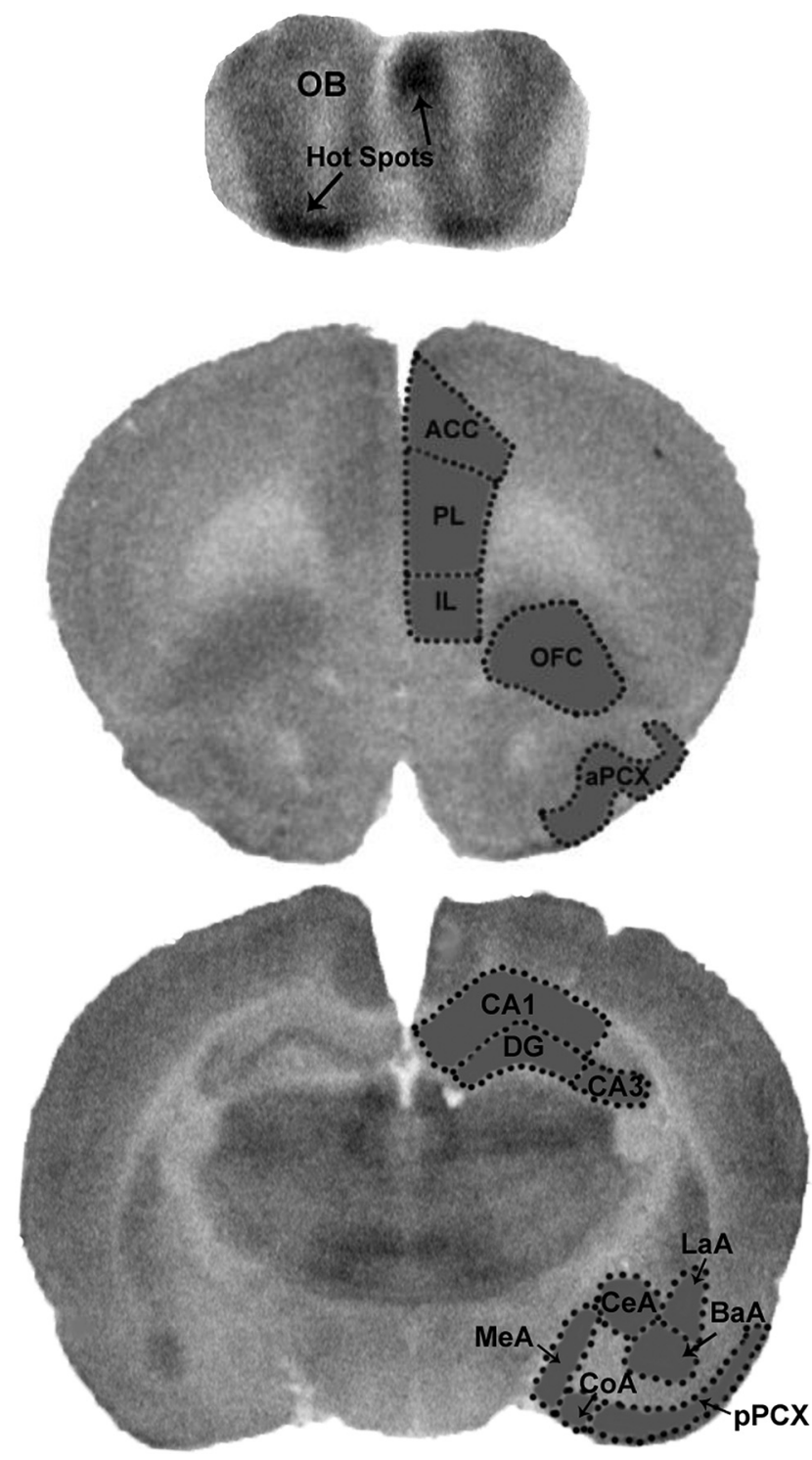

Figure 1. Representative autoradiographs of ${ }^{14} \mathrm{C} 2-\mathrm{DG}$ uptake displaying example glomerular "hot spots" within the $\mathrm{OB}$ and individual brain areas (right) where measurements were made in the PCX, OFC, hippocampus, and amygdala. ACC, Anterior cingulate cortex; PL, prelimbic cortex; IL, infralimbic cortex, DG, dentate gyrus of hippocampus.

Amygdala and hippocampus. Specific nuclei and anatomical landmarks were identified by staining sections with cresyl violet after exposure and used to make template overlays for the autoradiographs (Fig. 1; Moriceau et al., 2009; Raineki et al., 2010b; Debiec and Sullivan, 2014). Brain areas analyzed were medial $(\mathrm{MeA})$, lateral $(\mathrm{LaA})$, basal $(\mathrm{BaA})$, central $(\mathrm{CeA})$, and cortical (CoA) nuclei of the amygdala, as well as CA1, CA3, and dentate gyrus of the dorsal hippocampus.

$P C X, O F C$, and prefrontal cortex (PFC). Cresyl violet staining was not used for analysis of the PCX and OFC because anatomical landmarks are visible with 2-DG. With the aid of a stereotaxic atlas (Paxinos and Watson, 1986), brain areas were outlined (Fig. 1). The brain areas analyzed were aPCX, pPCX, and OFC.

\section{Statistical analysis}

Behavioral and 2-DG uptake data were analyzed by ANOVA followed by post hoc Fisher's tests between individual groups or Student's $t$ tests in cases with two experimental groups. Bivariate correlation matrices were created by computing ratios of mean 2-DG uptake for all pairwise combinations of brain regions analyzed for maternal, male, and no odor at each age. For quantitative analyses of functional connectivity, the differ- 


\section{A Saturated Odorants}

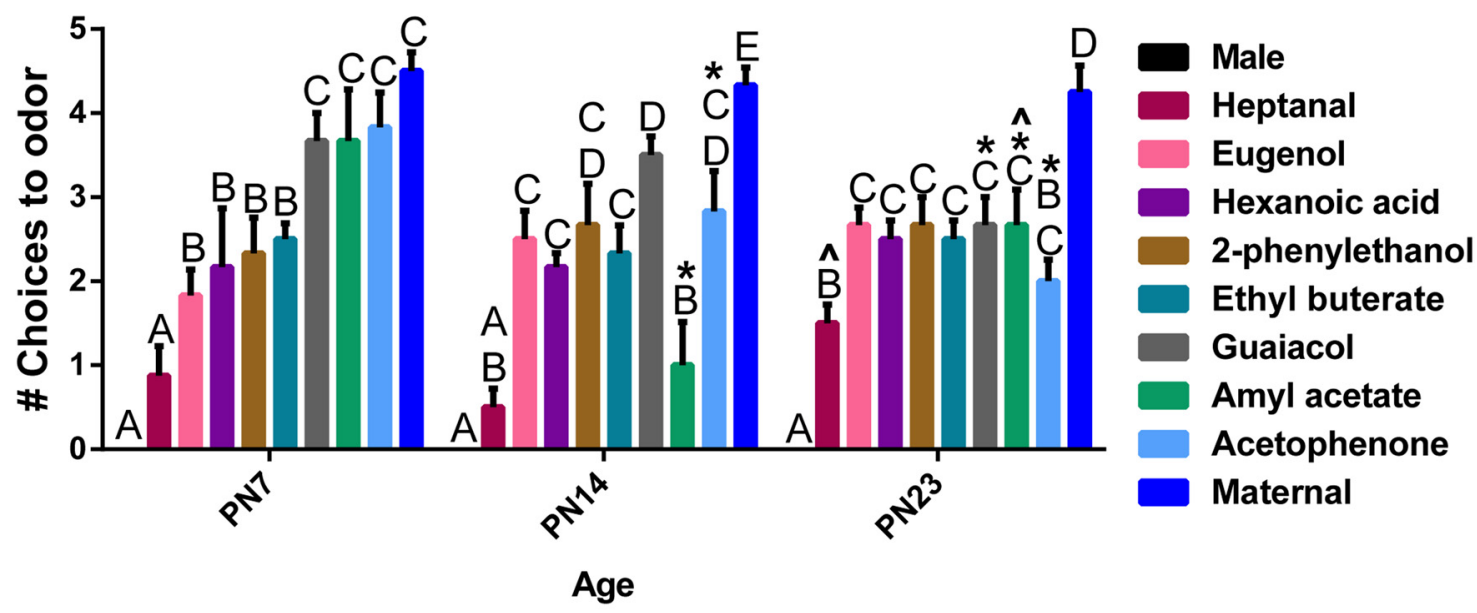

B 10 PPM Odorants

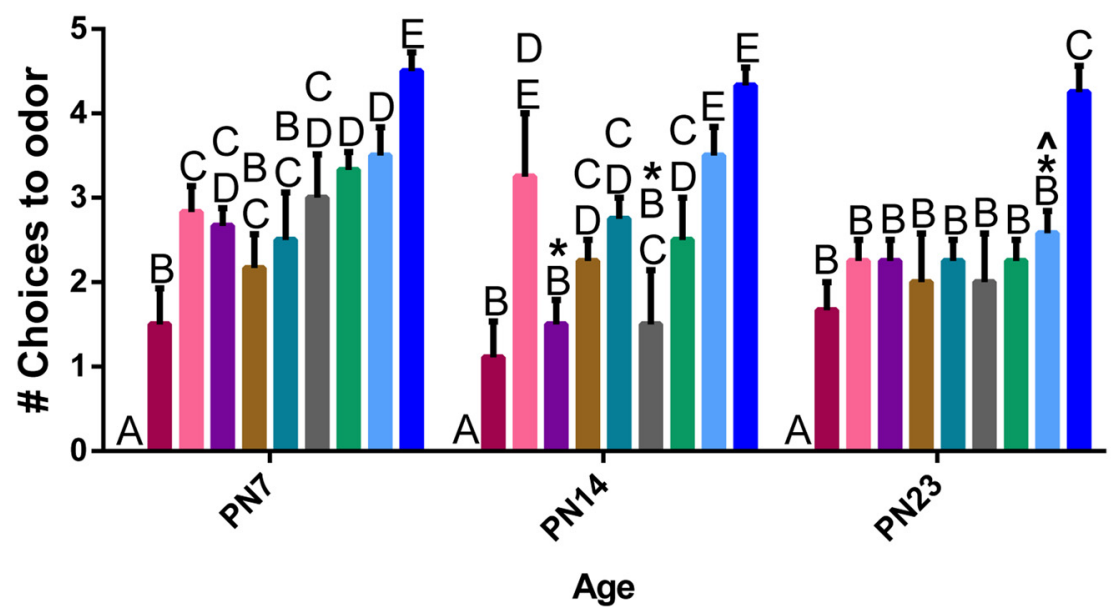

Figure 2. Mean ( \pm SEM) number of choices to saturated ( $\boldsymbol{A} ; 100$ PPM) and diluted ( $\boldsymbol{B} ; 10$ PPM) odorants during Y-maze testing of approach/avoidance across early development. Approach and avoidance responses to odorants remained relatively stable throughout development. Male odor consistently elicited the most avoidance and maternal odor consistently elicited the most approach across development. The response to maternal and male odor is plotted in both saturated and 10 PPM odorant graphs to allow comparison. Groups that share a common alphabetic label are not significantly different from each other within each age only based on post hoc tests ( $p<0.05, n=6-8$ for all groups). *Significant difference from same odor at PN7 based on post hoc tests ( $p<$ $0.05)$, ^significant difference from same odor at PN14 based on post hoc tests $(p<0.05)$.

ence between each odor's correlation matrix and the no odor correlation matrix was computed at each age and group differences were analyzed by ANOVA followed by post hoc Fisher's tests. All differences were considered significant when $p<0.05$.

\section{Results}

Experiment 1: the neurobehavioral development of odor hedonics

In Experiment 1, we assessed distributed brain regions both within and outside the primary olfactory pathway for their modulation of activity in concert with the hedonic valence of an odorant stimulus across ontogeny.

\section{Experiment 1a: behavior}

To first identify odors with varying hedonic valences, animals were tested in a two-odor choice Y-maze to determine hedonic approach/avoidance responses to eight artificial odors (saturated and diluted) and two naturalistic odors (maternal and male odor) across early development (Fig. $2 ; n=6-8$ animals for all groups). All Y-maze choices were made between the experimen- tal odor and a familiar odor (clean bedding), thus showing whether odors were of increasing or decreasing hedonic value relative to a familiar odor.

Pups showed statistically different responses to our collection of odorants throughout development for both saturated and diluted odors, as indicated by $3 \times 10$ ANOVA (factors of age and odor). For saturated odors, the ANOVA revealed a significant interaction between age and odor (Fig. $2 A ; F_{(18,158)}=3.077, p<$ $0.0001)$. Post hoc tests indicated that, although approach/avoidance responses to most odors remained stable across early development, approach to acetophenone and guaiacol declined with maturation, approach to heptanal increased with maturation, and amyl acetate was significantly more avoided at PN14 than at PN7 and PN23 $(p<0.05)$. Furthermore, post hoc tests indicated strong avoidance for male odor and approach for maternal odor relative to all other odors across early development $(p<0.05)$. For diluted (10 PPM) odors, no significant interaction between age and odor was found (Fig. $2 B ; F_{(18,175)}=1.071, p=0.3848$ ). However, the main effect of age $\left(F_{(2,175)}=3.690, p=0.0269\right)$ and 

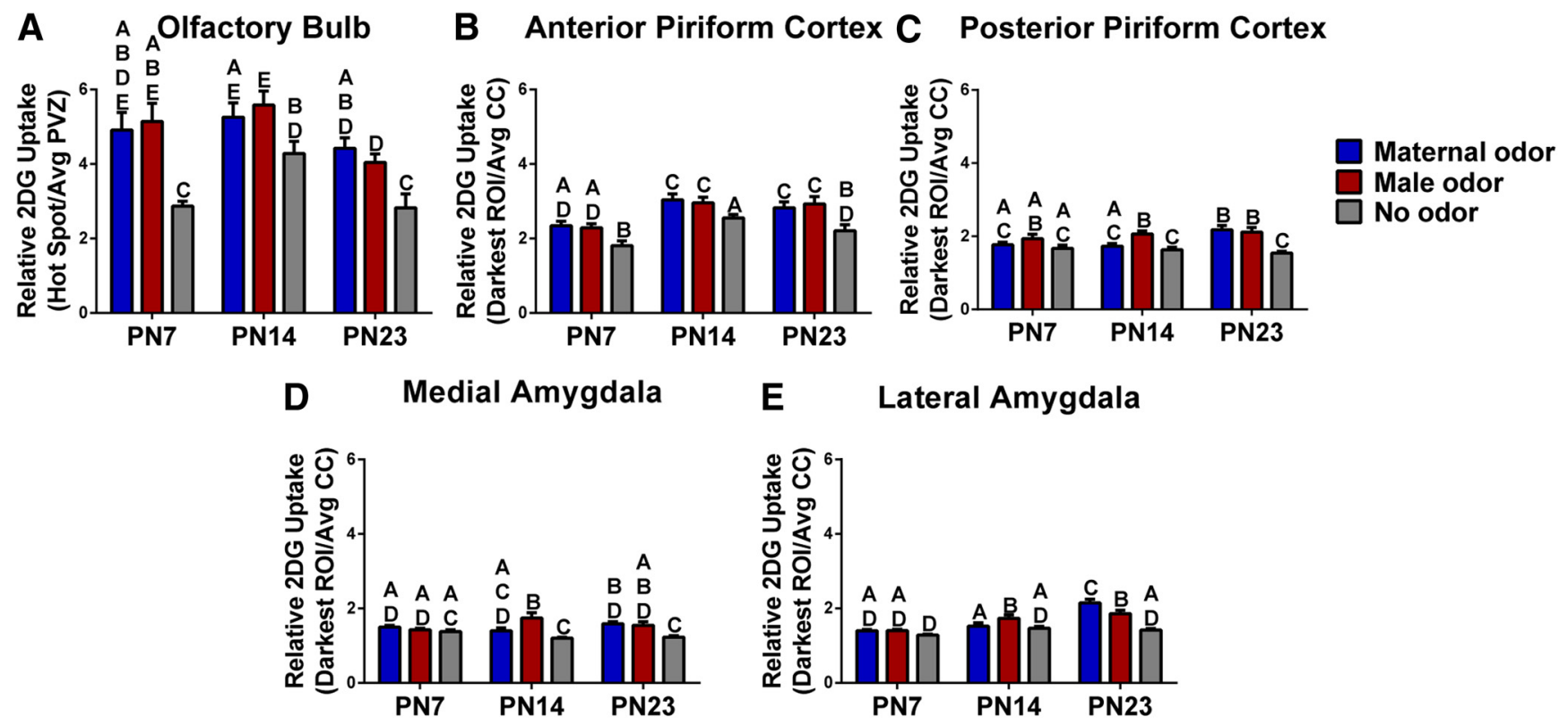

$\mathbf{F}$

CA1

G Orbitofrontal Cortex
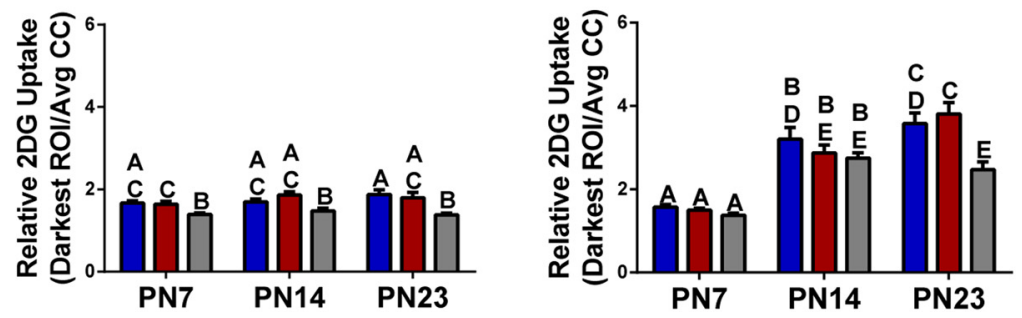

Figure 3. Mean ( \pm SEM) relative ${ }^{14}(2-D G$ uptake in response to maternal, male, or no odor presentations at PN7, $\mathrm{PN} 14$, and PN23 in 0B $(\boldsymbol{A})$, olfactory cortex ( $\boldsymbol{B}, \boldsymbol{C})$, amygdala $(\boldsymbol{D}, \boldsymbol{E})$, hippocampus $(\boldsymbol{F})$, and $0 \mathrm{FC}(\boldsymbol{G})$ ( $n=13-16$ for all groups). Groups that share a common alphabetic label are not significantly different from each other based on $p o s t$ hoc tests $(p<0.05)$. PVZ, Periventricular zone (of OB); CC, corpus callosum.

main effect of odor $\left(F_{(9,175)}=26.210, p<0.0001\right)$ were significant. Post hoc tests revealed groups of avoided odors, approached odors, and neutral odors that were not strongly approached or avoided at each age $(p<0.05)$. In addition, post hoc tests indicated that approach responses for hexanoic acid, guaiacol, and acetophenone declined with maturation $(p<0.05)$. When approach/avoidance responses to odors were analyzed with sex as a variable, no sex differences were found.

Overall, whereas some artificial odorants evoked relatively reliable approach/avoidance behaviors by PN7 and through weaning, the biological maternal and male odors evoked the most robust and stable responses at all ages tested.

Experiment 1b: neural assessment

To assess neural correlates underlying the development of approach/avoidance responses, animals were presented with male odor (most avoided) or maternal odor (most approached). After odor presentations, brains were removed and neural activity was assessed via 2-DG ROI analyses (Fig. 3) and functional connectivity analyses (Figs. 4, 5, 6). When 2-DG responses to odors were analyzed with sex as a variable, no sex differences were found. For all groups, $n=13-16$ animals per group (males and females).

$\mathrm{OB} /$ olfactory piriform cortices.

$O B$

To test the effect of age and odor on 2-DG uptake within glomerular "hot spots" of the OB (relative to 2-DG uptake within the periventricular zone), 2-DG uptake ratios were analyzed using a $3 \times 3$ ANOVA, with factors of age and odor. The ANOVA showed a significant main effect of age (Fig. $3 A ; F_{(2,118)}=7.807$, $p=0.0007$ ), with post hoc tests indicating a significant decrease in relative $2-\mathrm{DG}$ uptake to male odor by PN23 $(p<0.05)$. The main effect of odor was also significant $\left(F_{(2,118)}=12.700, p<0.0001\right)$, with post hoc tests showing significantly higher 2-DG uptake to maternal odor and male odor relative to no odor control conditions at all ages $(p<0.05)$. The interaction between odor and age was not significant $\left(F_{(4,118)}=0.799, p=0.5280\right)$.

\section{aPCX}

Similarly, a $3 \times 3$ ANOVA (factors of age and odor) was used to test the effect of age and odor on 2-DG uptake within the aPCX (relative to 2-DG uptake within the corpus callosum). A significant main effect of age was found (Fig. 3B; $F_{(2,125)}=17.300, p<0.0001$ ), with post hoc tests indicating significantly higher 2-DG uptake to maternal and male odor at PN14 and PN23 relative to PN7 $(p<0.05)$. The main effect of odor was also significant $\left(F_{(2,125)}=13.250, p<\right.$ 0.0001 ), with post hoc tests revealing significantly higher 2-DG uptake to maternal odor and male odor, relative to "no odor" at all ages $(p<0.05)$. The interaction between odor and age was not significant $\left(F_{(4,125)}=0.322, p=0.8629\right)$.

pPCX

Within the pPCX, a $3 \times 3$ ANOVA revealed a significant interaction between age and odor on relative 2-DG uptake (Fig. $3 C ; F_{(4,124)}=$ 


\section{Maternal}

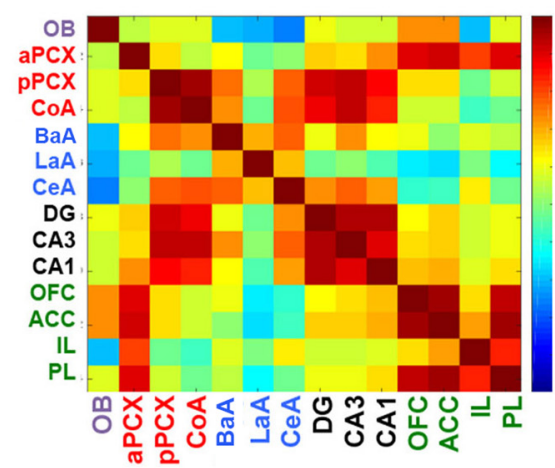

Male

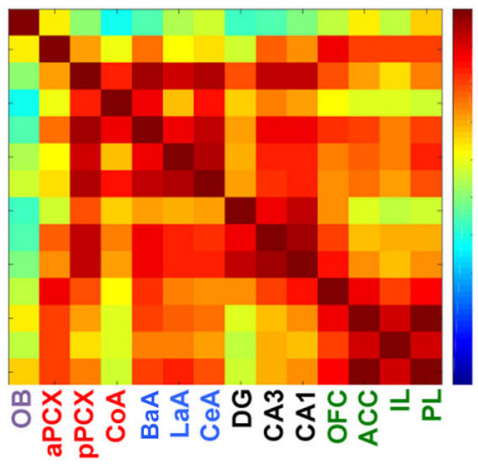

No odor

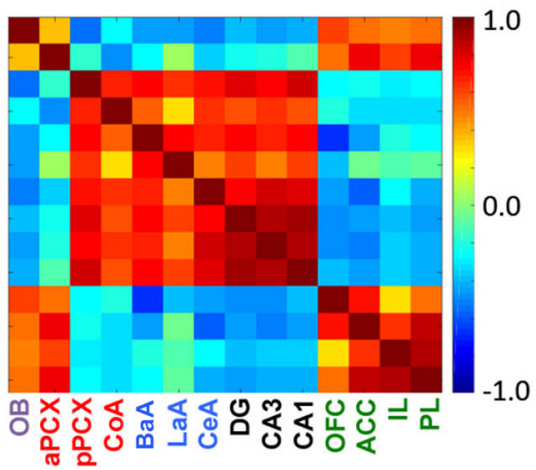

Figure 4. Bivariate correlation matrices representing the ratios of mean ${ }^{14} \mathrm{C} 2-\mathrm{DG}$ uptake calculated between all pairwise brain regions analyzed in response to maternal, male, or no odor presentations at PN14. Core olfactory areas are shown in purple and red, amygdala areas in blue, hippocampus subareas in black, and orbitofrontal and PCX areas in green. ACC, Anterior cingulate cortex; IL, infralimbic cortex; PL,prelimbic cortex.

$3.021, p=0.0204)$. By PN14, the pPCX was significantly activated by male odor only, whereas at PN23, both maternal and male odor significantly activated pPCX, as determined by post hoc tests $(p<$ $0.05)$. Furthermore, whereas relative $2-D G$ uptake remained stable across early development in response to male odor and no odor conditions, relative 2-DG uptake in response to maternal odor increased in the pPCX by PN23 (post hoc tests, $p<0.05$ ).

Therefore, within the primary olfactory regions, biologicalodor-evoked pPCX activity emerged later than the other regions and the pPCX was the only region to differentiate between maternal and male odor.

\section{Amygdala}

$\mathrm{MeA}$

A $3 \times 3$ ANOVA of relative 2-DG uptake within the MeA showed a significant interaction of age and odor (Fig. $3 D ; F_{(4,119)}=4.071$, $p=0.0040$ ). Post hoc tests indicated that, at PN14, the MeA was significantly activated by male odor only, whereas at PN23, male and maternal odor significantly activated the MeA $(p<0.05)$. In addition, whereas relative 2-DG uptake remained stable across development in response to maternal and no odor conditions, male odor was associated with heightened relative 2-DG uptake in the MeA by PN14 (post hoc tests, $p<0.05$ ).

\section{LaA}

In the LaA, a $3 \times 3$ ANOVA indicated a significant interaction between age and odor on relative 2-DG uptake (Fig. $3 E ; F_{(4,126)}=$ 7.529, $p<0.0001)$. At PN14, LaA activation was specific to male odor only (post hoc tests, $p<0.05$ ). At PN23, whereas both odors activated the LaA significantly more than the no odor condition, maternal odor was associated with significantly higher relative 2-DG uptake compared with the activation seen in response to male odor ( post hoc tests, $p<0.05$ ). Furthermore, relative 2-DG uptake within the LaA increased significantly in response to male odor by PN14 and to maternal odor by PN23 (post hoc tests, $p<0.05$ ).

\section{Hippocampus}

In CA1 of the dorsal hippocampus, a $3 \times 3$ ANOVA did not reveal a significant interaction of age and odor on relative 2-DG uptake $\left(F_{(4,126)}=1.140, p=0.3409\right)$. However, a significant main effect of odor was found (Fig. $3 F ; F_{(2,126)}=16.050, p<$ 0.0001). Post hoc tests indicated that male and maternal odor consistently activated the CA1 across early development relative to no odor. No significant main effect of age was found $\left(F_{(2,126)}=\right.$ 2.289, $p=0.1056)$.

\section{OFC}

A $3 \times 3$ ANOVA indicated a significant interaction of age and odor on relative 2 -DG uptake within the OFC (Fig. $3 G ; F_{(4,131)}=$ $3.876, p=0.0052)$. Post hoc tests revealed a general increase in relative 2-DG uptake within the OFC by PN14, with male odor and maternal odor activating the OFC significantly more than the no odor condition by PN23 $(p<0.05)$.

\section{Functional connectivity network analyses}

2-DG uptake data across individual animals for each brain region was used to construct bivariate correlation matrices for all pairwise combinations of brain regions analyzed for maternal, male, and no odor at each age ( $n=13-16$ pups/odor/age). For example, a single data point represents the correlation between 2-DG uptake in a given brain region across all animals at that age with uptake in a different region in the same animals. Therefore, functional connectivity here is defined as a covariation of activity in two brain regions across animals and does not imply a direct anatomical relationship. Additional areas to those outlined in our above ROI analyses were included (see ROI statistics for these additional regions in Table 1). Example matrices for each odor response at PN14 are shown in Figure 4. Large changes in basal functional connectivity across age to the no odor condition were found due to developmental changes in neural activity levels and anatomical connectivity. Therefore, for quantitative analysis, we created correlation matrices representing the difference between correlation matrices obtained for each biological odor and the no odor condition (bivariate correlation matrix for each odor - bivariate correlation matrix for no odor = "difference correlation matrix"). These matrices highlight change in relative functional connectivity between the no odor and odor conditions and are shown in Figure 5.

As illustrated in Figure 5, there are substantial changes between the difference correlation matrices across age and between odors. These changes were often observed in specific neural network modules. For example, a module between PFC (OFC, anterior cingulate cortex, infralimbic cortex, and prelimbic cortex) and amygdala (BaA, LaA, CeA)/hippocampus (DG, CA3, CA1) was apparent at both PN14 and PN23 (Fig. 6A), with enhanced functional connectivity within this module during exposure to male odor compared 


\section{Maternal}
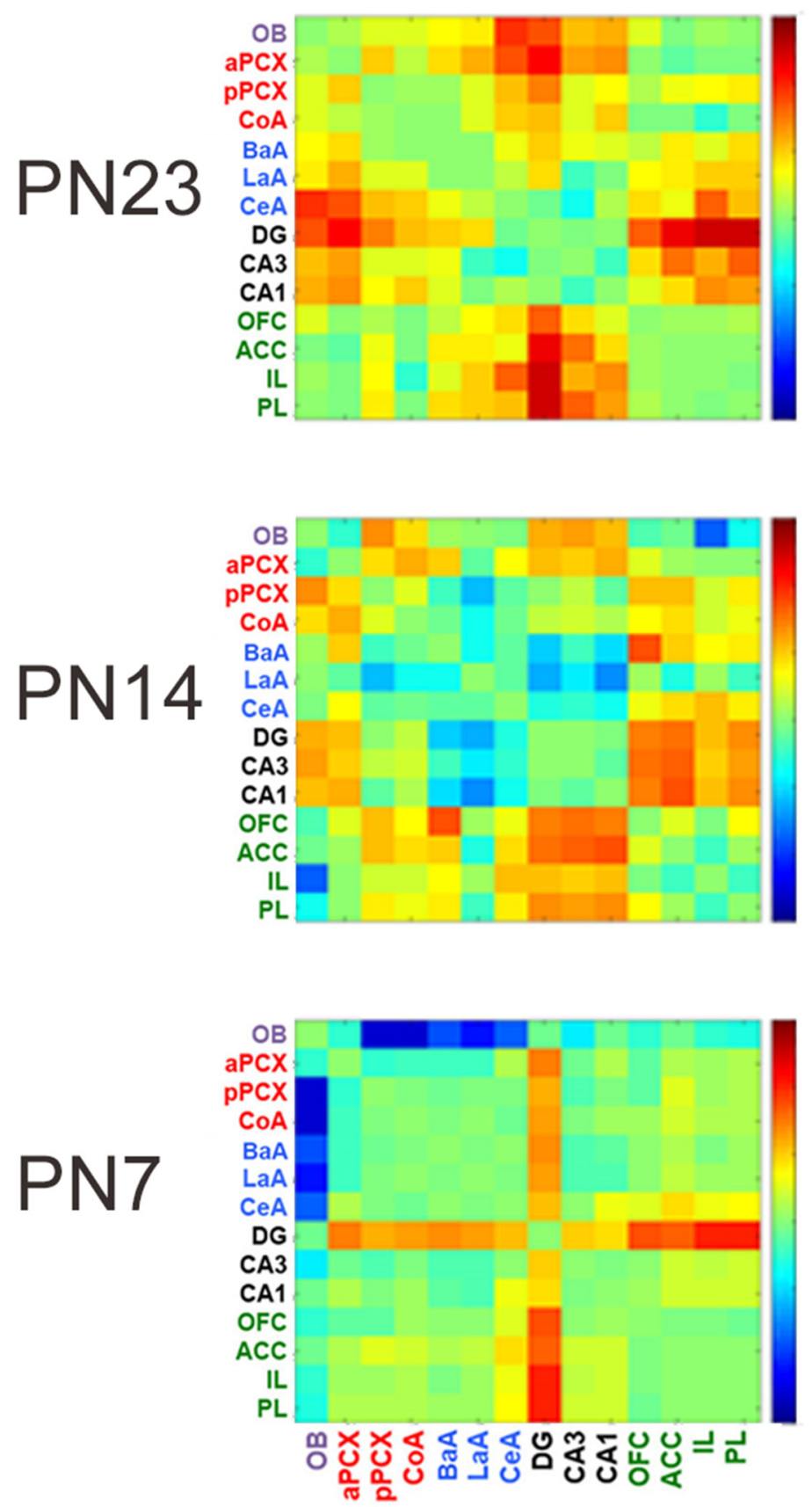

Male
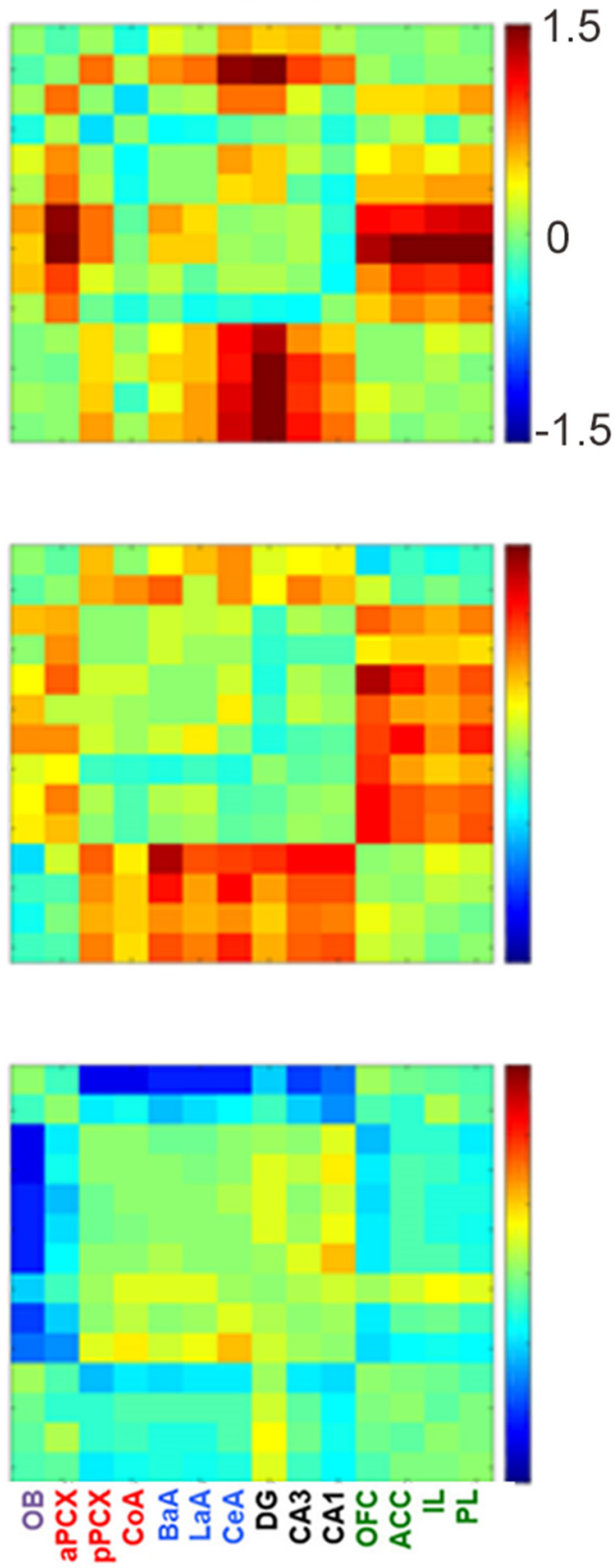

Figure 5. Correlation matrices representing the difference of ratios of mean ${ }^{14} \mathrm{C} 2-\mathrm{DG}$ uptake between each biological odor (male odor, maternal odor) and the no odor condition (bivariate correlation matrix for each odor - bivariate correlation matrix for no odor) at PN7, PN14, and PN23. Changes in functional connectivity across odors and ages can be observed in specific neural network modules. Core olfactory areas are shown in purple and red, amygdala areas in blue, hippocampus subareas in black, and orbitofrontal and PCX areas in green. ACC, Anterior cingulate cortex; IL, infralimbic cortex; PL, prelimbic cortex.

with maternal odor. A similar module emerged between the PFC and olfactory cortical areas (aPCX, pPCX and CoA), with, again, differential levels of connectivity in this module between maternal and male odor (Fig. 6B).

To compare the difference correlation matrices statistically across age and odor, correlations were converted to $z$-scores with a Fisher transform and mean difference $z$-scores within each module were analyzed with ANOVA (age $X$ odor; see Fig. 6). Although a variety of potential modules could be extracted from these data, as a starting point, we selected those that were most prominently different between odors in the matrices. The PFCamygdala/hippocampal formation module (Fig. 6) showed a significant main effect of age $\left(F_{(2,138)}=35.672, p<0.0001\right)$ and a significant age $\times$ odor interaction $\left(F_{(2,138)}=105.676, p<\right.$ $0.0001)$. Post hoc tests revealed enhanced relative functional connectivity in this module in response to male odor compared with maternal odor at PN14 and PN23, but reduced relative functional connectivity to male odor compared with maternal odor at PN7 $(p<0.01)$. Therefore, at PN7, male odor evoked a relative disconnect within this module compared with activity in response to 
A
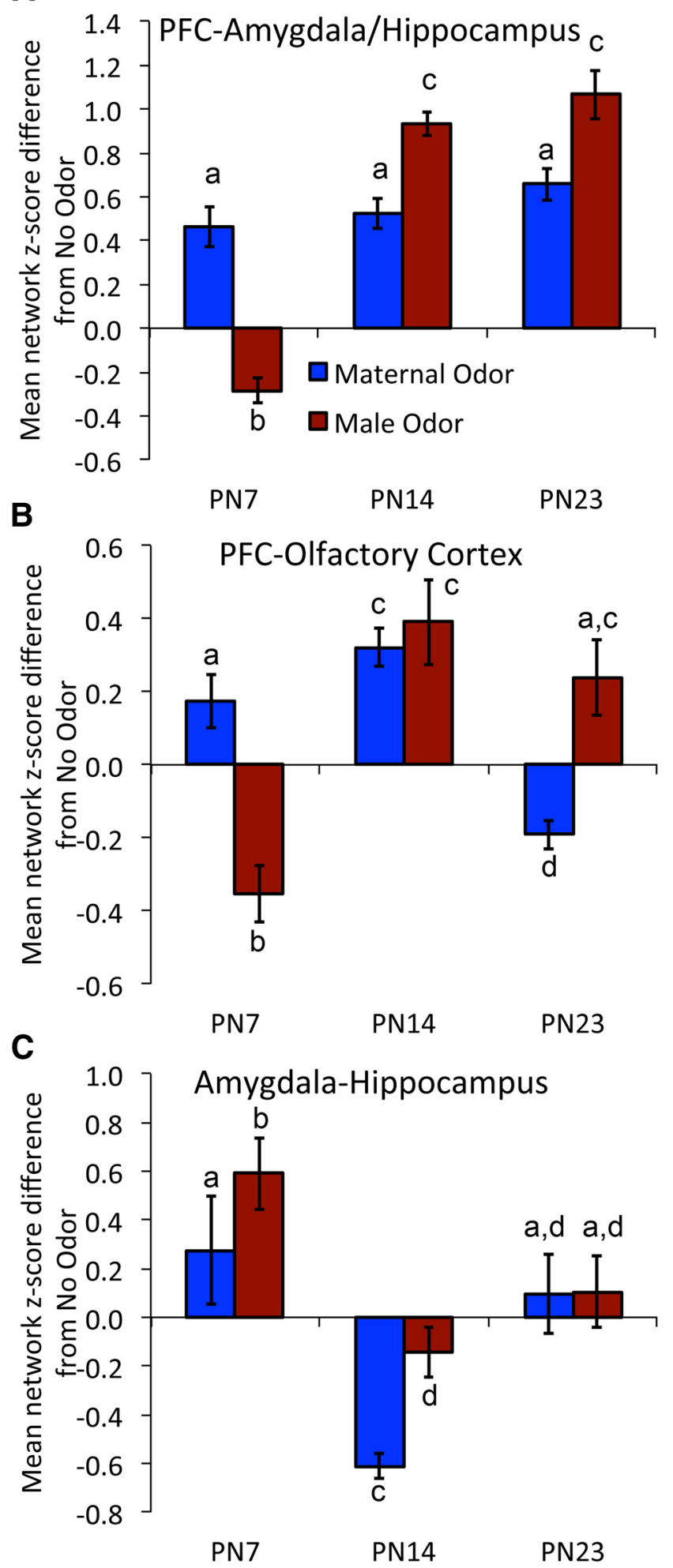

Figure 6. Mean difference in z-score-converted correlations of mean ${ }^{14} \mathrm{C} 2-\mathrm{DG}$ uptake between biological odors (male odor, maternal odor) and the no odor control condition in three different network modules across age. $\boldsymbol{A}$, PFC-Amygdala/hippocampus module. $\boldsymbol{B}$, PFColfactory cortex module. $C$, Amygdala-hippocampus module. Groups with the same alphabetic label are not significantly different from each other based on post hoc tests $(p<0.01)$.

maternal odor, whereas at PN14 and PN23, male odor instead enhanced connectivity within this module. Overall, relative functional connectivity in this module also increased significantly with age regardless of odor condition.
A similar pattern was evident in the PFC-olfactory cortex module (Fig. 6; main effect of age $F_{(2,66)}=16.058, p<0.0001$; age $\times$ odor interaction, $\left.F_{(2,66)}=17.519, p<0.0001\right)$. Male odor evoked enhanced relative functional connectivity compared with maternal odor at both PN14 and PN23 and decreased relative functional connectivity at PN7 (post hoc tests, $p<0.01$ ). Finally, relative functional connectivity with the amygdala-hippocampal formation module (Fig. 6) was more complex. There was a significant main effect of age $\left(F_{(2,48)}=14.877, p<0.0001\right)$, but no significant age $\times$ odor interaction $\left(F_{(2,48)}=1.218, p=0.304\right)$. The largest effect was a decrease in relative functional connectivity in response to maternal odor at PN14, with minimal odorspecific differences at other ages.

Overall, these neural data suggest increasing circuit complexity underlying odor hedonics during early life, as well as fundamental changes in processing by brain areas implicated in hedonics. For example, whereas predator odor is avoided throughout life, it produces amygdala-dependent freezing only after PN10 (Takahashi, 1992; Wiedenmayer and Barr, 2001b; Moriceau et al., 2004), which is supported by later-life activation of the amygdala (Fig. $3 N-O$ ). Similarly, the function of maternal odor also changes over development, as can be seen by its unique ability to block amygdala-learning-induced plasticity during stress conditioning between the ages of PN10 and PN15 (Moriceau and Sullivan, 2006; Upton and Sullivan, 2010).

Experiment 2: early life olfactory experience modulates the development of odor hedonics

To better understand hedonic circuitry, we next increased and/or decreased the hedonic value of maternal and predator odors, again using a naturalistic paradigm. Neural activity within the primary olfactory pathway is not only affected by odor quality and intensity (Kadohisa and Wilson, 2006; Wilson et al., 2006), but also by past experience (i.e., adaptation, perceptional learning, associative memories, behavioral state, and expectation; Pager et al., 1972; Gervais and Pager, 1979; Freeman and Skarda, 1985; Kay and Laurent, 1999; Gottfried and Dolan, 2003; Murakami et al., 2005; de Araujo et al., 2005; Li et al., 2006; Rinberg and Gelperin, 2006; Shepherd, 2006; Wilson et al., 2006; Gervais et al., 2007; Kobayakawa et al., 2007; Martin et al., 2007). Specifically, in Experiment 2, we assessed how varying early life experience, such as via increased/decreased experience with male or maternal odor, alters the neurobehavioral development of odor hedonics at PN14 and PN23.

\section{Experiment 2a: behavior}

Previous early life experience altered the behavioral hedonic responses to maternal and male odor, as illustrated in Figure 7. At PN14, a $2 \times 2$ ANOVA with factors of odor (maternal odor and male odor) and early life experience (control vs altered early life experience with odor) revealed a significant interaction of odor and early life experience (Fig. $7 A ; F_{(1,28)}=145.700, p<0.0001$, $n=8$ animals per group). Similarly, a $2 \times 2$ ANOVA with factors of odor and early life experience indicated a significant interaction at PN23 (Fig. $7 B ; F_{(1,27)}=111.800, p<0.0001, n=7-8$ animals per group). Post hoc tests revealed that being reared by a mother with suppressed natural maternal odor decreased the hedonics of maternal odor (decreased approach) relative to controls $(p<0.05)$. In addition, post hoc tests indicated that being reared with a male reversed the hedonics of male odor by switching male odor avoidance to approach $(p<0.05)$. This pattern was seen at both PN14 and PN23.

Furthermore, eliminating perinatal and infant exposure to maternal odor (by feeding the mother a diet that suppresses the 
Table 1. Summary of statistics for relative ${ }^{14} \mathrm{C} 2-\mathrm{DG}$ uptake in response to maternal, male, and no odor at PN7, PN14, and PN23 for brain regions included in functional connectivity analyses that were not depicted in Figure 3

\begin{tabular}{|c|c|c|c|c|c|c|c|c|c|c|c|c|c|}
\hline \multirow[b]{2}{*}{ ROI } & \multirow[b]{2}{*}{ Age } & \multicolumn{3}{|c|}{ Maternal odor } & \multicolumn{3}{|c|}{ Male odor } & \multicolumn{3}{|c|}{ No odor } & \multicolumn{3}{|l|}{ Statistics } \\
\hline & & Mean & SEM & $n$ & Mean & SEM & $n$ & Mean & SEM & $n$ & Age & Odor & Interaction \\
\hline \multirow[t]{2}{*}{$\mathrm{COA}$} & PN7 & 1.485 & 0.044 & 14 & 1.600 & 0.052 & 15 & 1.376 & 0.049 & 14 & $F=1.631$ & $F=19.880$ & $F=2.587$ \\
\hline & PN23 & 1.698 & 0.086 & 15 & 1.642 & 0.069 & 15 & 1.380 & 0.045 & 16 & & & \\
\hline \multirow[t]{3}{*}{$\mathrm{BaA}$} & PN7 & 1.433 & 0.037 & 14 & 1.511 & 0.057 & 16 & 1.368 & 0.043 & 14 & $F=46.010$ & $F=9.718$ & $F=7.227$ \\
\hline & PN14 & 1.648 & 0.099 & 16 & 1.870 & 0.095 & 14 & 1.685 & 0.081 & 15 & $p<0.0001^{*}$ & $p=0.0001^{*}$ & $p<0.0001^{*}$ \\
\hline & PN23 & 2.782 & 0.207 & 15 & 2.420 & 0.169 & 16 & 1.723 & 0.088 & 16 & & & \\
\hline CeA & PN23 & 1.626 & 0.061 & 15 & 1.528 & 0.067 & 16 & 1.259 & 0.032 & 16 & & & \\
\hline \multirow[t]{3}{*}{ DG } & PN7 & 1.661 & 0.063 & 15 & 1.745 & 0.109 & 16 & 1.420 & 0.050 & 14 & $F=14.830$ & $F=19.590$ & $F=0.885$ \\
\hline & PN14 & 1.656 & 0.074 & 16 & 1.798 & 0.069 & 15 & 1.414 & 0.045 & 15 & $p<0.0001^{*}$ & $p<0.0001^{*}$ & $p=0.4750$ \\
\hline & PN23 & 1.482 & 0.037 & 15 & 1.417 & 0.044 & 15 & 1.223 & 0.021 & 16 & & & \\
\hline \multirow[t]{2}{*}{ CA3 } & PN7 & 1.861 & 0.082 & 15 & 1.855 & 0.098 & 16 & 1.608 & 0.077 & 14 & $F=5.288$ & $F=16.120$ & $F=1.090$ \\
\hline & PN14 & 1.866 & 0.096 & 16 & 2.035 & 0.088 & 14 & 1.574 & 0.077 & 15 & $p=0.0062^{*}$ & $p<0.0001^{*}$ & $p=0.3644$ \\
\hline \multirow[t]{3}{*}{ IL } & PN7 & 1.346 & 0.017 & 14 & 1.313 & 0.021 & 15 & 1.259 & 0.018 & 15 & $F=81.830$ & $F=9.211$ & $F=4.803$ \\
\hline & PN14 & 1.448 & 0.039 & 15 & 1.471 & 0.029 & 15 & 1.422 & 0.039 & 16 & $p<0.0001^{*}$ & $p=0.0002^{*}$ & $p=0.0012^{*}$ \\
\hline & PN23 & 2.000 & 0.084 & 15 & 2.109 & 0.105 & 16 & 1.619 & 0.089 & 16 & & & \\
\hline \multirow[t]{3}{*}{ PL } & PN7 & 1.302 & 0.015 & 14 & 1.274 & 0.024 & 15 & 1.228 & 0.017 & 15 & $F=100.900$ & $F=4.815$ & $F=6.791$ \\
\hline & PN14 & 1.721 & 0.073 & 15 & 1.693 & 0.069 & 15 & 1.831 & 0.088 & 16 & $p<0.0001^{*}$ & $p=0.0096^{*}$ & $p<0.0001^{*}$ \\
\hline & PN23 & 2.582 & 0.135 & 15 & 2.726 & 0.161 & 16 & 1.940 & 0.144 & 16 & & & \\
\hline
\end{tabular}

Statistics reported include means, SEM, sample size $(n)$, main effects of age, main effects of odor, and age $\times$ odor interactions resulting from two-way ANOVA. ROI statistics are shown for additional brain areas included in Experiment 1 's functional connectivity analyses.

natural maternal odor) significantly increased latency time for nipple attachment at PN14 (Fig. $7 C ; t_{(16)}=21.430, p<0.0001$, $n=8-10$ animals per group). Interestingly, at PN23, maternal odor presentations no longer supported nipple attachment in this short test regardless of early life exposure to maternal odor (Fig. $7 D$; all SEM $=0, n=8$ animals per group). This reduced ability of maternal odor to control interactions with the mother in PN23 pups has been suggested by other research (Upton and Sullivan, 2010; Sarro et al., 2014), although the odor seems to change function and control other behaviors, including sexual behavior, in adulthood (Raineki et al., 2015).

When infants were exposed to male odor in their nest since birth by being reared with both their mother and father, they no longer displayed aversive responses to the odor in the Y-maze; rather, they displayed a preference for the male odor (Fig. $7 A, B$ ). Furthermore, whereas control animals (normal rearing without the male) displayed decreased activity (i.e., increased immobility/ freezing) in response to predator odor indicating continued threat processing of the odor (Wiedenmayer and Barr, 2001b; Wiedenmayer et al., 2003; Moriceau et al., 2004; Chen et al., 2006), rearing with a familiar male significantly increased mean activity scores during male odor presentations at PN14 (Fig. 7E; $t_{(14)}=4.674, p=0.0095, n=8$ animals per group) and PN23 (Fig. $7 F ; t_{(14)}=3.140, p=0.0349, n=8$ animals per group). For all behavior, when responses to odors were analyzed with sex as a variable, no sex differences were found.

\section{Experiment 2b: neural assessment of ROIs}

After the various rearing conditions to modify pups' hedonic response to maternal and male predator odor, we also assessed pups' brains using 2-DG autoradiography. Specifically, after early life rearing to alter maternal and male odor hedonics, PN14 and PN23, pups were injected with 2-DG and presented with adult male odor, maternal odor, or no odor (control), followed by brain removal. The goal of this experiment was to determine how tagging identical odors with different hedonic values (through previous life experience) would alter processing of the odor. This permitted the targeted identification of brain regions important for hedonic encoding. When 2-DG responses to odors were analyzed with sex as a variable, no sex differences were found. For all groups, $n=7-8$ animals per group (males and females).

\section{Olfactory piriform cortices}

aPCX

One-way ANOVAs indicated significant differences in relative 2-DG uptake in the aPCX at PN14 (Fig. $8 A ; F_{(4,33)}=2.933, p=$ 0.0316 ) and PN23 (Fig. $8 B ; F_{(4,34)}=2.738, p=0.0408$ ) after our rearing conditions. At both ages, post hoc tests did not reveal significant differences in 2-DG uptake in the aPCX in response to maternal odor after rearing with a suppressed natural maternal odor relative to control-reared animals exposed to maternal odor and no odor $(p<0.05)$. However, whereas control-reared animals show increased 2-DG uptake in response to male odor relative to the no odor condition, pups reared with a male did not show significantly higher 2-DG uptake relative to the no odor control condition $(p<0.05)$.

In addition, to test for changes in 2-DG uptake as a function of early life experience, $2 \times 2$ ANOVAs with factors of odor (male and maternal) and early life experience (control or altered odor experience) were also computed (and did not include no odor control data). Results did not show a significant interaction of odor and experience at PN14 $\left(F_{(1,27)}=0.226, p=0.6372\right)$ or PN23 $\left(F_{(1,28)}=1.916, p<0.1743\right)$. A main effect of experience was revealed at PN14 $\left(F_{(1,27)}=6.509, p=0.015\right)$, with post hoc tests indicating that altered experience with male odor is associated with a significant decrease in 2-DG uptake in response to male odor relative to control-reared animals $(p<0.05)$.

pPCX

At PN14, there were significant differences in relative 2-DG uptake in the pPCX as determined by one-way ANOVA (Fig. $8 C$; 
A

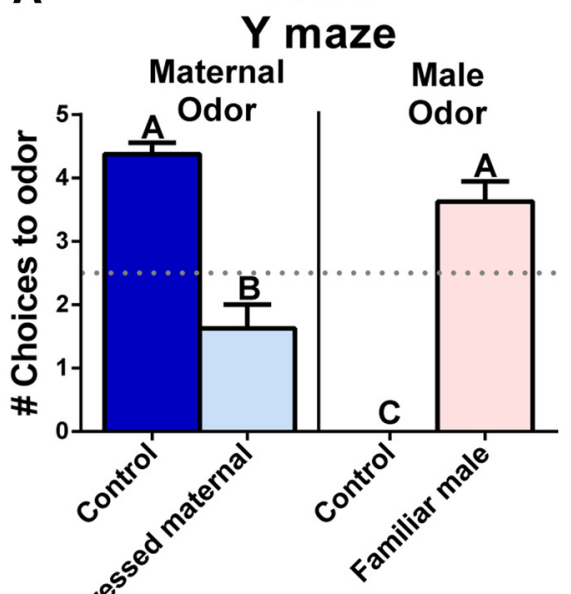

Early-life Experience

C

\section{PN14}

Nipple Attachment Maternal Odor

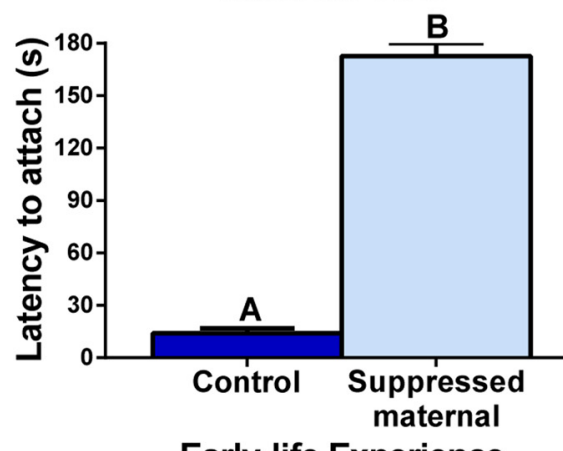

Early-life Experience

E

PN14

Activity Score

Male Odor

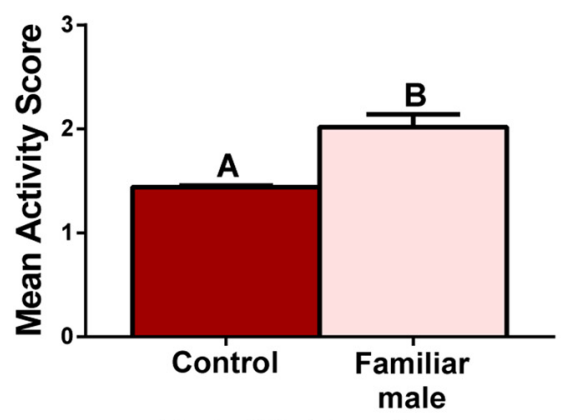

Early-life Experience
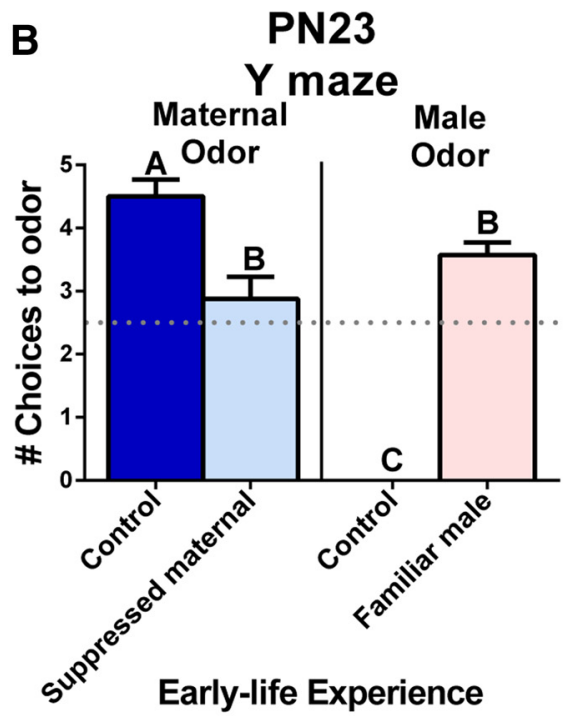

D

PN23

Nipple Attachment Maternal Odor

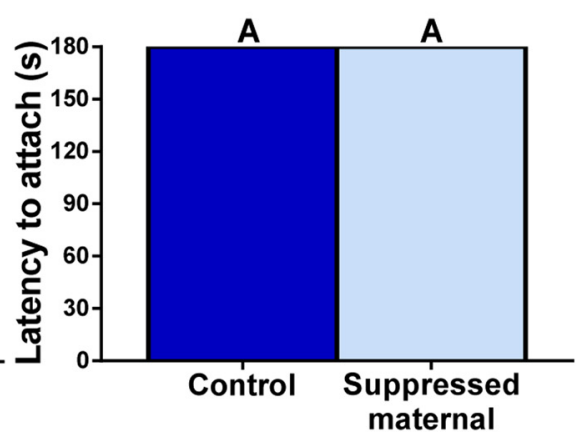

Early-life Experience

$\mathbf{F}$

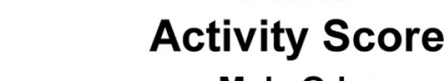

Male Odor

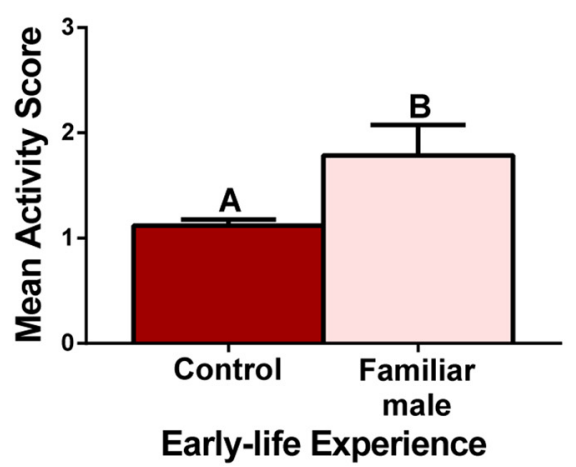

Figure 7. Early life experience alters behavioral responses to maternal and predator odor at PN14 and PN23 as assessed by mean ( \pm SEM) number of choices to male and maternal odor in a Y-maze $(\boldsymbol{A}, \boldsymbol{B} ; n=7-8 / \mathrm{group})$, mean ( \pm SEM) latency to nipple attach $(\boldsymbol{C}, \boldsymbol{D}$; $n=8-10$ /group), and mean ( \pm SEM) activity levels in response to male odor presentations $(\boldsymbol{E}, \boldsymbol{F} ; n=8 /$ group). Groups with the same alphabetic label are not significantly different from each other based on post hoc tests $(p<0.05)$.
$\left.F_{(4,33)}=5.429, p=0.0011\right)$ after our rearing conditions. Post hoc tests showed that rearing with suppressed natural maternal odor did not alter activity $(p<0.05)$. However, after co-rearing pups with a male, male odor was no longer associated with increased
pPCX activity relative to the no odor control condition (post hoc, $p<0.05$ ). At PN23, one-way ANOVA indicated significant differences in 2-DG activity in the pPCX (Fig. $8 D ; F_{(4,34)}=3.243, p=$ 0.0194). Post hoc tests indicated that control animals exposed to maternal odor and male odor displayed significant pPCX activation relative to no odor controls $(p<0.05)$. However, 2-DG uptake in the pPCX was no longer elevated relative to the no odor controls in response to maternal or male odor after rearing with suppressed natural maternal odor or a familiar male $(p<0.05)$.

To test for changes in relative $2-\mathrm{DG}$ uptake as a function of early life experience, $2 \times 2$ ANOVAs with factors of odor and early life experience were also computed (and did not include no odor control data). At PN14, a significant interaction between odor and experience was found $\left(F_{(1,27)}=4.391, p<0.0422\right)$, with post hoc tests indicating elevated relative 2-DG uptake to male odor in controlreared pups only $(p<0.05)$. No significant interactions $\left(F_{(1,28)}=0.004\right.$, $p=0.0953)$ or main effects (odor: $F_{(1,28)}$ $=0.156, p=0.6946$; experience: $F_{(1,28)}=$ 3.549, $p=0.0665$ ) were found at PN23.

\section{Amygdala}

$\mathrm{MeA}$

Our rearing conditions were associated with altered relative 2-DG uptake in response to male and maternal odors at PN14 (Fig. 8E; $F_{(4,33)}=5.438, p=0.0011$ ) and PN23 (Fig. $\left.8 F ; F_{(4,34)}=5.470, p=0.0010\right)$ as assessed by one-way ANOVA. At both ages, whereas male odor presentations to control animals were associated with increased 2-DG uptake in the MeA relative to the no odor condition, male odor presentations to animals reared with a male did not lead to an increase in 2-DG uptake (post hoc tests $p<$ $0.05)$. At PN23, maternal odor presentations to control pups and pups reared with suppressed maternal odor were associated with heightened 2-DG uptake relative to no odor control pups ( $p o s t$ hoc tests, $p<0.05$ ).

Additional $2 \times 2$ ANOVAs were conducted with factors of odor (maternal and male odor only) and early life experience (control and altered experience with odor). At PN14, a significant interaction of odor and experience was found $\left(F_{(1,27)}\right.$ $=4.715, p=0.0355)$ and post hoc tests showed elevated 2-DG uptake in control animal in response to male odor only $(p<0.05)$. At PN23, no significant interaction was found $\left(F_{(1,28)}\right.$ $=0.819, p=0.3705)$. A significant main effect of experience was found $\left(F_{(1,28)}=6.627, p=0.0137\right)$ and post hoc tests revealed that 
altered experience with male odor was associated with decreased 2-DG uptake in the $\operatorname{MeA}(p<0.05)$.

LaA

Early life experience altered relative 2-DG uptake in the LaA in response to male and maternal odors at PN14 (Fig. 8G; $F_{(4.33)}=$ 2.672, $p=0.0443$ ) and PN23 (Fig. $8 H$; $\left.F_{(4,34)}=6.411, p=0.0003\right)$ as determined by one-way ANOVA. At PN14, post hoc tests indicated significantly increased 2-DG uptake in response to male odor after control rearing relative to all other groups $(p<0.05)$. At PN23, post hoc tests revealed elevated 2-DG activity in response to male and maternal odor in control animals relative to no odor controls $(p<0.05)$. However, pups reared with suppressed maternal odor or a familiar male did not show the same elevated responses to male and maternal odor relative to the no odor condition (post hoc tests, $p<0.05)$.

ANOVAs $(2 \times 2)$ with factors of odor (male and maternal odor only) and early life experience revealed no significant interactions at $\operatorname{PN} 14\left(F_{(1,27)}=2.262\right.$, $p=0.1411)$ or $\operatorname{PN} 23\left(F_{(1,28)}=0.529\right.$, $p=0.4709)$. However, a main effect of experience was revealed at PN23 $\left(F_{(1,28)}\right.$ $=6.931, p=0.0118)$, with post hoc tests indicating that altered experience with maternal odor, but not male odor, decreased 2-DG uptake in the LaA $(p<$ 0.05).

\section{Hippocampus}

Early life experience altered relative 2-DG uptake in CA1 of the hippocampus at PN14 (Fig. 8I; $F_{(4,33)}=4.997, p=0.0020$ ) and PN23 (Fig. 8J; $F_{(4,34)}=4.288, p=$ $0.0046)$ as indicated by one-way ANOVA. At both PN14 and PN23, post hoc tests revealed increased CA1 activity to male and maternal odor in control-reared animals relative to the no odor condition $(p<0.05)$. However, after rearing with a male or rearing with suppressed natural maternal odor, CA1 activity was no longer elevated relative to the no odor control condition $(p<0.05)$.

Additional $2 \times 2$ ANOVAs conducted using factors of odor (male and maternal odor only) and early life experience did not result in significant interactions at PN14 $\left(F_{(1,27)}=0.435, p=0.5136\right)$ or $\operatorname{PN} 23\left(F_{(1,28)}=0.008, p=0.9294\right)$. Significant main effects of experience were found at PN14 $\left(F_{(1,27)}=12.790, p=\right.$ $0.0009)$ and PN23 $\left(F_{(1,28)}=9.236, p=\right.$ $0.0041)$ and post hoc tests showed that altered early life experience with male and
A

PN14

Anterior Piriform Cortex

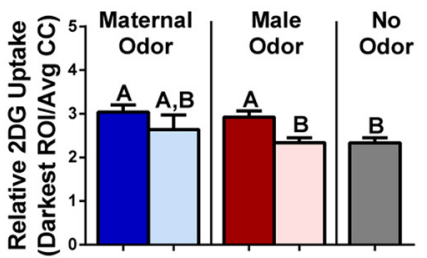

Early-life Experience
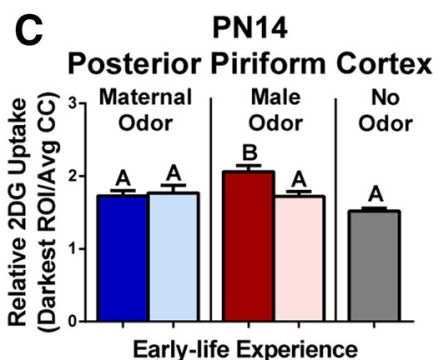

E

PN14

Medial Amygdala

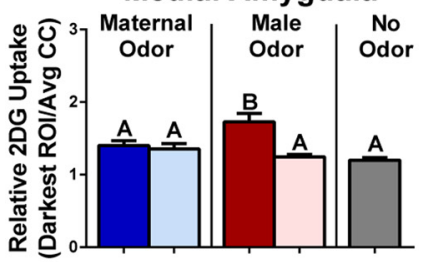

Early-life Experience
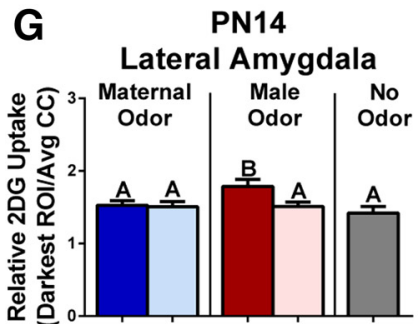

Early-life Experience

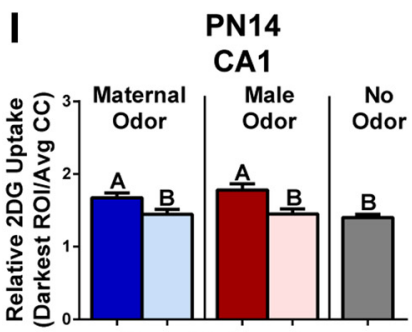

Early-life Experience

K

PN14

Orbitofrontal Cortex

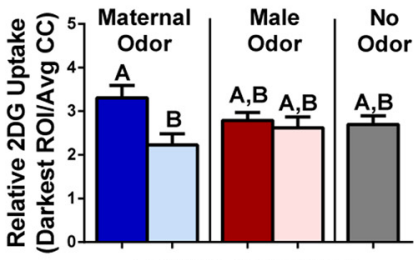

Early-life Experience
B $\begin{aligned} & \text { PN23 } \\ & \text { Anterior Piriform Cortex }\end{aligned}$

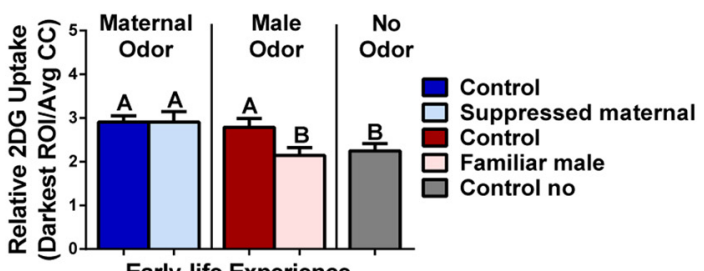

Early-life Experience

PN23

Posterior Piriform Cortex

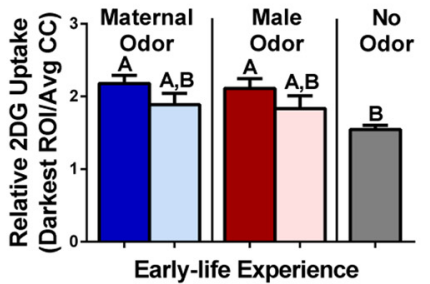

F PN23

Medial Amygdala

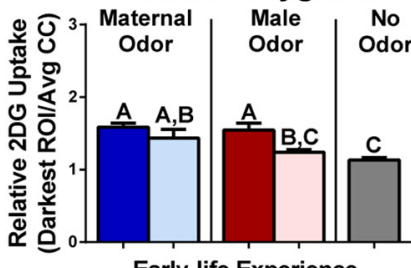

Early-life Experience

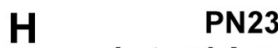

Lateral Amygdala

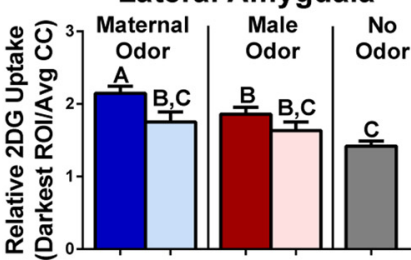

Early-life Experience

$\mathbf{J}$

PN23

CA1

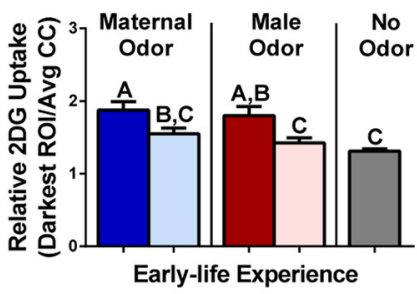

L PN23

Orbitofrontal Cortex

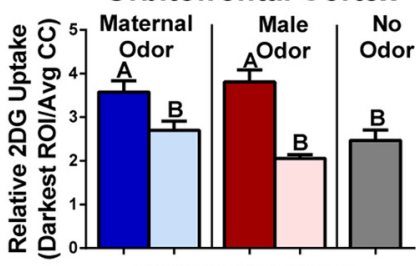

Early-life Experience

Figure 8. Mean ( \pm SEM) relative ${ }^{14} \mathrm{C} 2-\mathrm{DG}$ uptake in response to maternal, male, or no odor presentations at PN14, and 23 in olfactory cortex $(\boldsymbol{A}-\boldsymbol{D})$, amygdala $(\boldsymbol{E}-\boldsymbol{H})$, hippocampus $(\boldsymbol{I}, \boldsymbol{J})$, and $\mathrm{OFC}(\boldsymbol{K}, \boldsymbol{L})$ as a function of previous early life experience. Axes ranges were equated for each brain region. $n=7-8$ for all groups. Groups with a common alphabetic label are not significantly different from each other based on post hoc tests $(p<0.05)$. CC, Corpus callosum. 
Table 2. Summary of statistics for relative ${ }^{14} \mathrm{C} 2$-DG uptake in response to maternal, male, and no odor at PN23 for brain regions included in functional connectivity analyses that were not depicted in Figure 8

\begin{tabular}{|c|c|c|c|c|c|c|c|c|c|c|c|c|c|c|}
\hline \multirow{2}{*}{\multicolumn{2}{|c|}{$\begin{array}{l}\text { ROI } \\
\text { Experience }\end{array}$}} & \multicolumn{4}{|l|}{ Maternal odor } & \multicolumn{4}{|l|}{ Male odor } & \multirow{2}{*}{\multicolumn{2}{|c|}{$\frac{\text { No odor }}{\text { Control }}$}} & \multirow{2}{*}{\multicolumn{3}{|c|}{ Statistics }} \\
\hline & & \multicolumn{2}{|l|}{ Control } & \multicolumn{2}{|l|}{ Suppressed } & \multicolumn{2}{|l|}{ Control } & \multicolumn{2}{|l|}{ Familiar } & & & & & \\
\hline & Age & Mean & $n$ & Mean & $n$ & Mean & $n$ & Mean & $n$ & Mean & $n$ & Experience & Odor & Interaction \\
\hline $\mathrm{COA}$ & PN23 & $1.732( \pm 0.124)$ & 8 & $1.657( \pm 0.142)$ & 8 & $1.727( \pm 0.099)$ & 8 & $1.518( \pm 0.096)$ & 8 & $1.448( \pm 0.061)$ & 8 & $\begin{array}{l}F=1.478 \\
p=0.234\end{array}$ & $\begin{array}{l}F=0.380 \\
p=0.543\end{array}$ & $\begin{array}{l}F=0.329 \\
p=0.571\end{array}$ \\
\hline $\mathrm{BaA}$ & PN23 & $2.823( \pm 0.289)$ & 8 & $2.771( \pm 0.447)$ & 8 & $2.437( \pm 0.277)$ & 8 & $2.096( \pm 0.212)$ & 8 & $1.799( \pm 0.148)$ & 8 & $\begin{array}{l}F=0.381 \\
p=0.542\end{array}$ & $\begin{array}{l}F=2.780 \\
p=0.107\end{array}$ & $\begin{array}{l}F=0.206 \\
p=0.653\end{array}$ \\
\hline CeA & PN23 & $1.710( \pm 0.099)$ & 8 & $1.245( \pm 0.033)$ & 8 & $1.594( \pm 0.093)$ & 8 & $1.378( \pm 0.088)$ & 8 & $1.199( \pm 0.042)$ & 8 & $\begin{array}{l}F=17.000 \\
p=0.0003^{*}\end{array}$ & $\begin{array}{l}F=0.011 \\
p=0.919\end{array}$ & $\begin{array}{l}F=2.273 \\
p=0.143\end{array}$ \\
\hline$D G$ & PN23 & $1.474( \pm 0.058)$ & 8 & $1.255( \pm 0.054)$ & 8 & $1.440( \pm 0.062)$ & 8 & $1.183( \pm 0.033)$ & 8 & $1.183( \pm 0.028)$ & 8 & $\begin{array}{l}F=20.21 \\
p=0.0001^{*}\end{array}$ & $\begin{array}{l}F=1.002 \\
p=0.325\end{array}$ & $\begin{array}{l}F=0.129 \\
p=0.722\end{array}$ \\
\hline CA3 & PN23 & $1.864( \pm 0.174)$ & 8 & $1.512( \pm 0.088)$ & 7 & $1.750( \pm 0.135)$ & 8 & $1.454( \pm 0.083)$ & 8 & $1.308( \pm 0.055)$ & 8 & $\begin{array}{l}F=6.388 \\
p=0.0176^{*}\end{array}$ & $\begin{array}{l}F=0.450 \\
p=0.508\end{array}$ & $\begin{array}{l}F=0.048 \\
p=0.829\end{array}$ \\
\hline $\mathrm{ACC}$ & PN23 & $2.713( \pm 0.168)$ & 8 & $2.322( \pm 0.169)$ & 8 & $2.841( \pm 0.172)$ & 8 & $1.969( \pm 0.125)$ & 8 & $2.301( \pm 0.227)$ & 8 & $\begin{array}{l}F=15.640 \\
p=0.0005^{*}\end{array}$ & $\begin{array}{l}F=0.496 \\
p=0.487\end{array}$ & $\begin{array}{l}F=2.268 \\
p=0.143\end{array}$ \\
\hline IL & PN23 & $2.039( \pm 0.104)$ & 8 & $1.858( \pm 0.111)$ & 8 & $2.148( \pm 0.151)$ & 8 & $1.617( \pm 0.097)$ & 8 & $1.511( \pm 0.121)$ & 8 & $\begin{array}{l}F=9.159 \\
p=0.005^{*}\end{array}$ & $\begin{array}{l}F=0.315 \\
p=0.579\end{array}$ & $\begin{array}{l}F=2.213 \\
p=0.148\end{array}$ \\
\hline$P L$ & PN23 & $2.644( \pm 0.160)$ & 8 & $2.385( \pm 0.191)$ & 8 & $2.882( \pm 0.153)$ & 8 & $1.997( \pm 0.122)$ & 8 & $1.704( \pm 0.128)$ & 8 & $\begin{array}{l}F=13.040 \\
p=0.001^{*}\end{array}$ & $\begin{array}{l}F=0.224 \\
p=0.639\end{array}$ & $\begin{array}{l}F=3.904 \\
p=0.058\end{array}$ \\
\hline
\end{tabular}

Statistics reported include means $( \pm \mathrm{SEM})$, sample size $(n)$, main effects of early life experience, main effects of odor, and odor $\times$ early-life experience interactions resulting from two-way ANOVA. ROI statistics are shown for additional brain areas included in Experiment 2's functional connectivity analyses.

maternal odor decreased 2-DG uptake in CA1 relative to controlreared pups at both ages $(p<0.05)$.

\section{OFC}

One-way ANOVAs revealed that early life experience altered relative 2-DG uptake in the OFC at PN14 (Fig. $8 K ; F_{(4,33)}=2.583$, $p=0.0497$ ) and PN23 (Fig. $8 L ; F_{(4,34)}=8.147, p<0.0001$ ). At PN14, 2-DG uptake in the OFC was decreased in response to maternal odor after rearing with suppressed maternal odor relative to control-reared pups ( $p o s t$ hoc tests, $p<0.05$ ). At PN23, 2 -DG uptake was heightened in control animals exposed to maternal and male odor relative to the no odor control condition, but was not heightened in pups reared with suppressed maternal odor or a familiar male, respectively (post hoc tests, $p<0.05$ ).

Additional $2 \times 2$ ANOVAs using factors of odor (male and maternal odor only) and early life experience did not reveal a significant interaction at PN14 $\left(F_{(1,27)}=2.954, p=0.0936\right)$ or PN23 $\left(F_{(1,28)}=2.423, p=0.1269\right)$. At PN14, a significant main effect of experience was found $\left(F_{(1,27)}=5.452, p=0.0248\right)$ and post hoc tests indicated that altered previous experience with maternal odor was associated with decreased 2-DG uptake in the OFC relative to control-reared pups $(p<0.05)$. At PN23, a significant main effect of experience was also found $\left(F_{(1,28)}=\right.$ 21.950, $p<0.0001$ ) and post hoc tests revealed that altered previous experience with both male and maternal odor was associated with decreased 2-DG uptake in the OFC relative to controlreared pups $(p<0.05)$.

\section{Functional connectivity network analyses}

Due to the large numbers of animals required for our functional connectivity analyses, only functional connectivity at PN23 was assessed. Additional areas to those outlined in our ROI analyses were included (see ROI statistics for these additional regions in Table 2). Difference correlation matrices were determined as described above by subtracting odor-evoked matrices from the no odor condition in PN23 pups after different developmental experiences. For statistical analyses, correlations were converted to $z$-scores as described above.
As shown in Figure 9, both odor quality and developmental experience shaped network functional connectivity during odor stimulation. Representative difference correlation pseudocolor plots are shown in Figure $9 \mathrm{~A}$ in pups exposed to male odor after either normal rearing with a mother only (male control) or after rearing with both mother and father (male familiar). As described above, male predator odor induced strong activation of the PFC-amygdala/hippocampal network module. However, in pups reared with a male, which therefore show an approach response to male odor, activity in this module was reduced and not significantly different from that evoked by maternal odor (Fig. 9B1; one-way ANOVA, $\left.F_{(3,95)}=8.234, p<0.0001\right)$. Post hoc tests revealed that functional connectivity in this module was significantly higher in controls exposed to male odor than to maternal odor and that pups reared with males were not significantly different from maternal odor control pups. Functional connectivity in this module in the presence of male odor was not affected by rearing with a mother that had the natural maternal odor suppressed. Therefore, functional connectivity in this module in part reflects hedonic preference, with activity in response to the same male odor shaped by the innate or learned response to this odor.

A similar relationship was observed in the functional connectivity within the PFC-olfactory cortex module. Again, male odor evoked stronger connectivity within this module than did maternal odor (Fig. 9B2), although developmental exposure to males modified the response to male odor $\left(\right.$ ANOVA, $\left.F_{(3,47)}=7.774, p<0.0003\right)$.

Finally, functional connectivity within the amygdalahippocampal network module appeared to reflect, not odor quality (male/maternal), but rather past experience (Fig. 9B3; $\left.F_{(3,35)}=6.156, p=0.0020\right)$. Functional connectivity in this module showed enhancement in those animals with modified developmental experience (raised with male and mother or raised with the maternal odor suppressed) compared with control pups when exposed to either the male or maternal odor. 


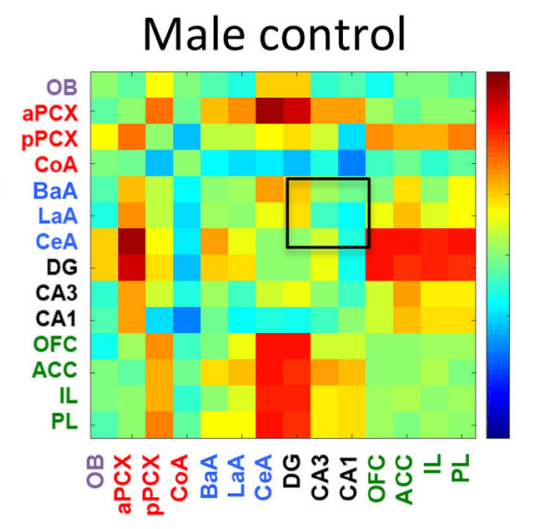

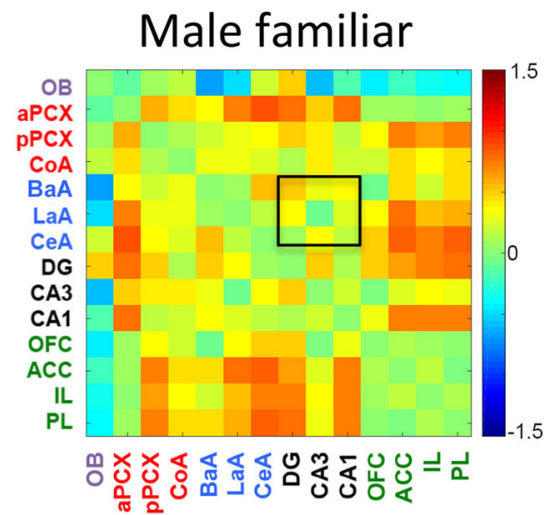

B1

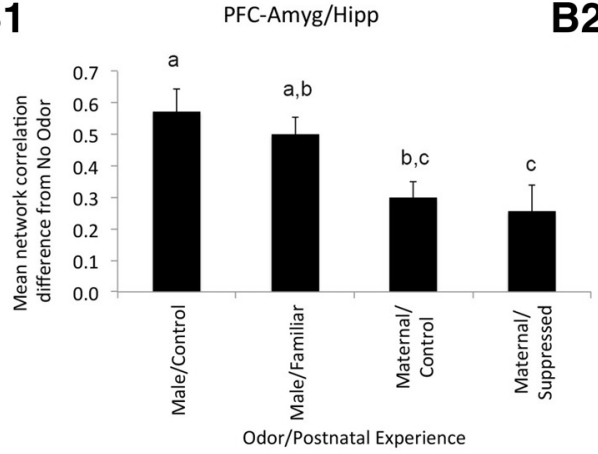

B2

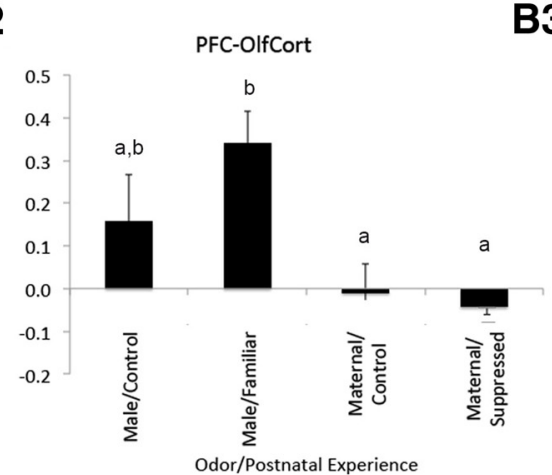

B3

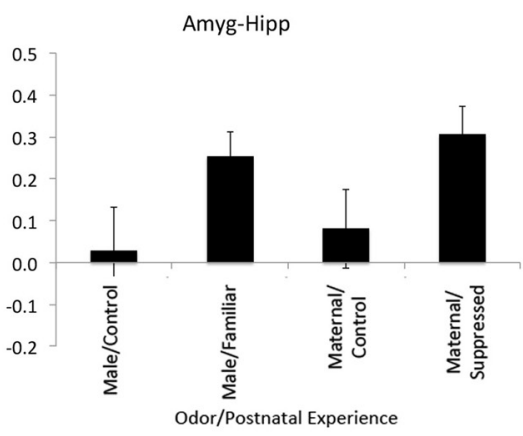

Figure 9. A, Correlation difference matrices of networks active during exposure to male odor with the no odor condition subtracted out. PN23 animals were exposed to male odor after having been raised with the mother alone (male control) or raised in the presence of a male (male familiar). Black outline highlights the amygdala-hippocampal network module. B1, Mean network correlations in response to each odor sorted by network module. As shown in Experiment 1, male odor induced stronger functional connectivity in the PFC-amygdala/hippocampal network module than maternal odor. However, being raised with a male (male/familiar) resulted in functional connectivity in this module no longer being significantly different from maternal odor in control rats. B2, In the PFC- olfactory cortex module, again, male odor induced relatively higher functional connectivity than maternal odor, although previous developmental experience with males significantly enhanced connectivity relative to all other conditions. B3, Learning to modify behavioral responses to odors during the postnatal period (male familiar and maternal suppressed) enhanced functional connectivity in the amygdala- hippocampal module relative to controls. Histogram bars marked with the same letter are not significantly different from each other based on post hoc comparisons $(p<0.05)$. Core olfactory areas are shown in purple and red, amygdala areas in blue, hippocampus subareas in black, and orbitofrontal and PCX areas in green. ACC, Anterior cingulate cortex; IL, infralimbic cortex; PL, prelimbic cortex.

\section{Discussion}

Odor cues guide approach and avoidance behaviors starting at birth in many mammals, including humans (Schmidt and Beauchamp, 1988; Varendi and Porter, 2001; Moriceau et al., 2004; Al Ain et al., 2016). Odor cues are essential for newborn rodents to approach their mother and attach to her nipples (Singh and Tobach, 1975; Hill and Almli, 1981) and suppress ultrasonic vocalizations in the presence of a predator (Conely and Bell, 1978; Takahashi, 1992). The present results describe the neural networks involved in these early emerging hedonic responses to biologically important odors. Our results show that the hedonic values of male (strongly avoided) and maternal (strongly approached) odors remained relatively stable throughout development, whereas those of monomolecular odors were more variable. The neural circuitry associated with these biological odors, however, was age and experience dependent. It must be noted that the 2-DG responses observed here reflect both the activity evoked by sensory input itself and the activity from the behavioral/autonomic response to that stimulus, which when combined, allow hedonic expression.

Recognizing and responding appropriately to odors that have learned or unlearned hedonic valences involves a large neural network including the olfactory cortex, amygdala, and prefrontal areas. Components of this network develop at different rates, so we hypothesized variation in hedonic-dependent regional activ- ity across development despite relative stability in behavioral outcome. This hypothesis was supported by our results. It should be noted that our analyses were primarily of entire brain regions and ignored any potential intraregional developmental or hedonic based spatial variation (Illig, 2007; Root et al., 2014). Future work will investigate these more fine-scaled network changes.

\section{Maternal odor}

For infant rodents, the maternal odor is critical for survival. It is required for nipple attachment and mother-infant interactions and suppresses amygdala activity to prevent threat learning that could cause pups to avoid their caregiver (Singh and Tobach, 1975; Hill and Almli, 1981; Sullivan et al., 2000; Moriceau and Sullivan, 2006; Raineki et al., 2010c). Therefore, not surprisingly, we found strong approach toward maternal odor at all ages assessed and maternal odor control of nipple attachment at PN14, consistent with previous findings (Teicher and Blass, 1977; Raineki et al., 2010a). By PN23, maternal odor no longer controlled nipple attachment, indicating a weakened hedonic value, as suggested previously (Upton and Sullivan, 2010; Sarro et al., 2014).

At PN7, maternal odor evoked significant activation of the primary olfactory pathway, including the $\mathrm{OB}$ and aPCX. In early infancy, these brain regions have a critical role in supporting mother-infant interactions and keeping pups within the nest, specifically via an OB/aPCX-dependent circuit that supports 
strong odor preference learning (Moriceau and Sullivan, 2004a; Moriceau et al., 2010; Landers and Sullivan, 2012; Morrison et al., 2013). Beyond the primary olfactory system, maternal odor activated hippocampal CA1.

At PN14, OB, aPCX, and CA1 responses to maternal odor remained stable. However, our functional connectivity analyses revealed that maternal odor was associated with a strong inverse correlation of amygdala-hippocampus activity at PN14 only. It is noteworthy that maternal odor has very particular control over pups at this age (PN10-PN15). Specifically, pups at this age are in a "transitional sensitive period" in which maternal stimuli have the unique ability to prevent threat learning through amygdala suppression (Moriceau and Sullivan, 2006; Upton and Sullivan, 2010). Therefore, these age-specific functional connectivity changes between the amygdala and hippocampus could contribute to the strong contextual control that maternal presence provides over pup learning during this age.

Our ROI analysis suggested an expansion of areas activated by maternal odor at PN23, particularly within the pPCX, amygdala, and OFC. This expanded maternal odor circuitry may underlie a shift in maternal odor's control of pup behavior as pups approach independence. Specifically, maternal odor no longer controls nipple attachment, suggesting a decrease of maternal odor's hedonic value (Sarro et al., 2014). However, maternal odor's behavioral control may switch, as indicated by its ability to dampen later life threat learning (Sevelinges et al., 2007), maintained approach toward maternal odor, and enhancement of sexual behavior by maternal odor (Raineki et al., 2015). The increased amygdala activation by maternal odor at PN23 may underlie its maintained positive hedonic value beyond weaning. Indeed, the amygdala, in particular the dorsal posterior MeA, mediates reproductive behavior (Dielenberg et al., 2001; McGregor et al., 2004).

Maternal odor presentations induced heightened functional connectivity within PFC-amygdala/hippocampus and PFC-olfactory cortex at PN14 and PN23. The PFC has been implicated in children's responses to maternal cues (Gee et al., 2014; Parma et al., 2014) and adult responses to safety cues (Schiller et al., 2008; Eisenberger et al., 2011). However, amygdala-hippocampus functional connectivity, which was suppressed at PN14, increased significantly at PN23 in response to maternal odor. Interestingly, this shift in functional connectivity emerges at the time that hippocampal-dependent contextual learning develops (Raineki et al., 2010b).

\section{Male odor}

Adult male rats commit infanticide against alien young pups, presumably to increase the opportunities to breed (Mennella and Moltz, 1988). Therefore, in infant rat pups, novel male odor is a predator odor that stops ultrasonic vocalizations during the earliest days of life and causes immobility/freezing in older pups beginning at PN10 (Brown, 1986; Takahashi, 1992; Hofer et al., 2002; Moriceau et al., 2004). We found strong avoidance of male odor at all ages assessed.

Similarly to maternal odor, male odor also activated the $\mathrm{OB}$, aPCX, and CA1 at PN7. The OB and aPCX are activated in response to predator odor in adults, suggesting that these areas underlie the response to predator odor throughout development (Murakami et al., 2012; Takahashi, 2014). In addition, at PN14, the pPCX, LaA, MeA, and CA1 were activated selectively by male odor, but not by maternal odor. Furthermore, a significant increase in activity in response to male odor occurred in the aPCX, amygdala, and OFC at PN14 relative to PN7. The specific contri- butions of these diverse areas in the infant response to predator odor are not known, although the results suggest increasing diversity of active regions as animals mature. Our results are divergent from a previous study in which no significant hippocampus activation was found in response to male odor at PN7 (Wiedenmayer and Barr, 2001a). However, that study presented male odor to huddled groups, whereas we tested our pups in isolation. Therefore, social-buffering-related effects from the presence of other pups may explain this difference (Sullivan and Perry, 2015).

In addition, we saw odor-specific differences in our functional connectivity analysis. At PN7, male odor produced decreased functional connectivity of the PFC with the amygdala (LaA, bAmyg, CeA), hippocampus (CA1, CA3, DG), and olfactory cortex (aPCX, pPCX, CoA), whereas maternal odor was associated with increased functional connectivity of the PFC with these regions. As pups aged, male odor induced stronger functional connectivity in these networks. In humans, fear-related functional connectivity within the PFC has been found to increase with development (Yurgelun-Todd and Killgore, 2006).

\section{Response plasticity}

To better understand the circuitry supporting odor hedonics, we altered the hedonic value of maternal and male odors by altering pups' developmental experience. By modifying the valence of the odor, we were able to identify circuits relevant for hedonic responses in isolation from the specific identity and/or intensity of the odor (Barr et al., 2009).

For example, eliminating pups' experience with maternal odor to reduce hedonic properties of maternal odor (e.g., disrupted nipple attachment) decreased CA1 and OFC activation at PN14 and PN23, as well as decreased activation of LaA at PN23, suggesting that these areas may be important for hedonic tagging of appetitive odors. Indeed, the OFC (Rolls et al., 1996; Schoenbaum et al., 1999; Berridge and Kringelbach, 2008) and LaA (Fuzzo et al., 2015; Ahern et al., 2016) have been implicated in processing positive odor hedonics.

The most dramatic effects, however, were observed in male odor responses. Co-rearing pups with a familiar adult male produced strong approach to male odor at PN14 and PN23. Corearing also decreased activation of most areas activated by male odor in control conditions at PN14 (aPCX, pPCX, MeA, LaA, CA1) and PN23 (aPCX, MeA, CA1, OFC). At PN14 and PN23, decreased activity was found in the aPCX, suggesting a fundamental difference in the processing of male odor after this switch of hedonic value (Nacher et al., 2004; Roth and Sullivan, 2005; Moriceau et al., 2006; Wilson and Sullivan, 2011). Furthermore, the pPCX, which has been implicated in aversive odor hedonic tagging within the context of threat conditioning, showed decreased activation at PN14, but not PN23, suggesting that this area may be important for aversive odor hedonics of innately threatening stimuli in infancy only (Chan et al., 2011; Li, 2014). The decrease in MeA activity is consistent with lesion data showing reduced freezing to predator odor in infancy (Chen et al., 2006) and adulthood (Blanchard et al., 2005) after MeA lesions. Finally, our functional connectivity data show that connectivity within the PFC-amygdala-hippocampal module, which is normally high in response to male odor and low to maternal odor, shifts to be more maternal-like in pups raised with a male.

Plasticity is a common feature throughout the olfactory system and is mediated by a variety of mechanisms (Barkai and Wilson, 2014). For example, developmental odor learning has been shown to involve selective changes in the OB (Sullivan et al., 1989; Yuan et al., 2003), PCX (Mukherjee et al., 2015), and 
amygdala (Barr et al., 2009). However, the specific sites and mechanisms required for the plasticity seen here have not been fully determined.

In summary, the neurobehavioral response to odors differing in hedonic meaning is shaped by both the developmental niche of the animal and its early life experience, not just the physicochemical properties of the odorants. Understanding the development of odor hedonics provides important insight into the development of sensory processes, food preferences, and the formation of social affiliations, among other behaviors.

\section{References}

Ahern M, Goodell DJ, Adams J, Bland ST (2016) Brain regional differences in social encounter-induced Fos expression in male and female rats after post-weaning social isolation. Brain Res 1630:120-133. CrossRef Medline

Al Ain S, Perry RE, Nunez B, Kayser K, Hochman C, Brehman E, LaComb M, Wilson DA, Sullivan RM (2016) Neurobehavioral assessment of maternal odor in developing rat pups: implications for social buffering. Soc Neurosci. In press.

Anderson AK, Christoff K, Stappen I, Panitz D, Ghahremani DG, Glover G, Gabrieli JD, Sobel N (2003) Dissociated neural representations of intensity and valence in human olfaction. Nat Neurosci 6:196-202. CrossRef Medline

Barkai E, Wilson DA (2014) Odor memory and perception. Prog Brain Res 208:ix-x. CrossRef Medline

Barr GA, Moriceau S, Shionoya K, Muzny K, Gao P, Wang S, Sullivan RM (2009) Transitions in infant learning are modulated by dopamine in the amygdala. Nat Neurosci 12:1367-1369. CrossRef Medline

Berridge KC, Kringelbach ML (2008) Affective neuroscience of pleasure: reward in humans and animals. Psychopharmacology (Berl) 199:457480. CrossRef Medline

Blanchard DC, Canteras NS, Markham CM, Pentkowski NS, Blanchard RJ (2005) Lesions of structures showing FOS expression to cat presentation: effects on responsivity to a Cat, Cat odor, and nonpredator threat. Neurosci Biobehav Rev 29:1243-1253. CrossRef Medline

Boulanger Bertolus J, Hegoburu C, Ahers JL, Londen E, Rousselot J, Szyba K, Thévenet M, Sullivan-Wilson TA, Doyère V, Sullivan RM, Mouly AM (2014) Infant rats can learn time intervals before the maturation of the striatum: evidence from odor fear conditioning. Front Behav Neurosci 8:176. CrossRef Medline

Brown RE (1986) Social and hormonal factors influencing infanticide and its suppression in adult male Long-Evans rats (Rattus norvegicus). J Comp Psychol 100:155-161. CrossRef Medline

Chan T, Kyere K, Davis BR, Shemyakin A, Kabitzke PA, Shair HN, Barr GA, Wiedenmayer CP (2011) The role of the medial prefrontal cortex in innate fear regulation in infants, juveniles, and adolescents. J Neurosci 31:4991-4999. CrossRef Medline

Chen SW, Shemyakin A, Wiedenmayer CP (2006) The role of the amygdala and olfaction in unconditioned fear in developing rats. J Neurosci 26:233240. CrossRef Medline

Conely L, Bell RW (1978) Neonatal ultrasounds elicited by odor cues. Dev Psychobiol 11:193-197. CrossRef Medline

Coopersmith R, Henderson SR, Leon M (1986) Odor specificity of the enhanced neural response following early odor experience in rats. Brain Res 392:191-197. Medline

Cunningham MG, Bhattacharyya S, Benes FM (2002) Amygdalo-cortical sprouting continues into early adulthood: implications for the development of normal and abnormal function during adolescence. J Comp Neurol 453:116-130. CrossRef Medline

de Araujo IE, Rolls ET, Velazco MI, Margot C, Cayeux I (2005) Cognitive modulation of olfactory processing. Neuron 46:671-679. CrossRef Medline

Debiec J, Sullivan RM (2014) Intergenerational transmission of emotional trauma through amygdala-dependent mother-to-infant transfer of specific fear. Proc Natl Acad Sci U S A 111:12222-12227. CrossRef Medline

Dias BG, Ressler KJ (2014) Parental olfactory experience influences behavior and neural structure in subsequent generations. Nat Neurosci 17: 89-96. CrossRef Medline

Dielenberg RA, Hunt GE, McGregor IS (2001) "When a rat smells a cat": the distribution of Fos immunoreactivity in rat brain following exposure to a predatory odor. Neuroscience 104:1085-1097. CrossRef Medline
Doty RL (1986) Odor-guided behavior in mammals. Experientia 42: 257-271. CrossRef Medline

Doty RL (2003) Handbook of olfaction and gustation, Ed 2. New York: Marcel Dekker.

Eisenberger NI, Master SL, Inagaki TK, Taylor SE, Shirinyan D, Lieberman MD, Naliboff BD (2011) Attachment figures activate a safety signalrelated neural region and reduce pain experience. Proc Natl Acad Sci U S A 108:11721-11726. CrossRef Medline

Fillion TJ, Blass EM (1986) Infantile experience with suckling odors determines adult sexual behavior in male rats. Science 231:729-731. CrossRef Medline

Freeman WJ, Skarda CA (1985) Spatial EEG patterns, non-linear dynamics and perception: the neo-Sherringtonian view. Brain Res 357:147-175. Medline

Fuster JM (2002) Frontal lobe and cognitive development. J Neurocytol 31: 373-385. CrossRef Medline

Fuzzo F, Matsumoto J, Kiyokawa Y, Takeuchi Y, Ono T, Nishijo H (2015) Social buffering suppresses fear-associated activation of the lateral amygdala in male rats: behavioral and neurophysiological evidence. Front Neurosci 9:99. CrossRef Medline

Gee DG, Gabard-Durnam L, Telzer EH, Humphreys KL, Goff B, Shapiro M, Flannery J, Lumian DS, Fareri DS, Caldera C, Tottenham N (2014) Maternal buffering of human amygdala-prefrontal circuitry during childhood but not during adolescence. Psychol Sci 25:2067-2078. CrossRef Medline

Gervais R, Pager J (1979) Combined modulating effects of the general arousal and the specific hunger arousal on the olfactory bulb responses in the rat. Electroencephalogr Clin Neurophysiol 46:87-94. CrossRef Medline

Gervais R, Buonviso N, Martin C, Ravel N (2007) What do electrophysiological studies tell us about processing at the olfactory bulb level? J Physiol Paris 101:40-45. CrossRef Medline

Gottfried JA (2006) Smell: central nervous processing. Adv Otorhinolaryngol 63:44-69. Medline

Gottfried JA (2007) What can an orbitofrontal cortex-endowed animal do with smells? Ann N Y Acad Sci 1121:102-120. CrossRef Medline

Gottfried JA, Dolan RJ (2003) The nose smells what the eye sees: crossmodal visual facilitation of human olfactory perception. Neuron 39:375-386. CrossRef Medline

Gottfried JA, O’Doherty J, Dolan RJ (2002) Appetitive and aversive olfactory learning in humans studied using event-related functional magnetic resonance imaging. J Neurosci 22:10829-10837. Medline

Herz RS, Beland SL, Hellerstein M (2004) Changing odor hedonic perception through emotional associations in humans. Int J Comp Psychol 17: 315-338.

Hill DL, Almli CR (1981) Olfactory bulbectomy in infant rats: survival, growth and ingestive behaviors. Physiol Behav 27:811-817. CrossRef Medline

Hofer MA (1994) Hidden regulators in attachment, separation, and loss. Monogr Soc Res Child Dev 59:192-207. CrossRef Medline

Hofer MA, Shair H, Singh P (1976) Evidence that maternal ventral skin substances promote suckling in infant rats. Physiol Behav 17:131-136. CrossRef Medline

Hofer MA, Shair HN, Brunelli SA (2002) Ultrasonic vocalizations in rat and mouse pups. Curr Protoc Neurosci Chapter 8:Unit 8.14. CrossRef Medline

Illig KR (2007) Developmental changes in odor-evoked activity in rat piriform cortex. Neuroscience 145:370-376. CrossRef Medline

Jin J, Zelano C, Gottfried JA, Mohanty A (2015) Human amygdala represents the complete spectrum of subjective valence. J Neurosci 35:1514515156. CrossRef Medline

Johnson BA, Leon M (2007) Chemotopic odorant coding in a mammalian olfactory system. J Comp Neurol 503:1-34. CrossRef Medline

Johnson BA, Woo CC, Ninomiya-Tsuboi K, Leon M (1996) Synaptophysinlike immunoreactivity in the rat olfactory bulb during postnatal development and after restricted early olfactory experience. Brain Res Dev Brain Res 92:24-30. CrossRef Medline

Kadohisa M, Wilson DA (2006) Separate encoding of identity and similarity of complex familiar odors in piriform cortex. Proc Natl Acad Sci U S A 103:15206-15211. CrossRef Medline

Kass MD, Rosenthal MC, Pottackal J, McGann JP (2013) Fear learning en- 
hances neural responses to threat-predictive sensory stimuli. Science 342: 1389-1392. CrossRef Medline

Kay LM, Laurent G (1999) Odor- and context-dependent modulation of mitral cell activity in behaving rats. Nat Neurosci 2:1003-1009. CrossRef Medline

Khan RM, Luk CH, Flinker A, Aggarwal A, Lapid H, Haddad R, Sobel N (2007) Predicting odor pleasantness from odorant structure: pleasantness as a reflection of the physical world. J Neurosci 27:10015-10023. CrossRef Medline

Kobayakawa K, Kobayakawa R, Matsumoto H, Oka Y, Imai T, Ikawa M, Okabe M, Ikeda T, Itohara S, Kikusui T, Mori K, Sakano H (2007) Innate versus learned odour processing in the mouse olfactory bulb. Nature 450:503-508. CrossRef Medline

Lancet D, Greer CA, Kauer JS, Shepherd GM (1982) Mapping of odorrelated neuronal activity in the olfactory bulb by high-resolution 2-deoxyglucose autoradiography. Proc Natl Acad Sci U S A 79:670-674. CrossRef Medline

Landers MS, Sullivan RM (1999) Vibrissae-evoked behavior and conditioning before functional ontogeny of the somatosensory vibrissae cortex. J Neurosci 19:5131-5137. Medline

Landers MS, Sullivan RM (2012) The development and neurobiology of infant attachment and fear. Dev Neurosci 34:101-114. CrossRef Medline

Leon M (1975) Dietary control of maternal pheromone in the lactating rat. Physiol Behav 14:311-319. CrossRef Medline

Leon M (1980) Development of olfactory attraction by young Norway rats. In: Chemical signals (Muller-Schware D, Silverstein RM, eds). New York: Plenum.

Li W (2014) Learning to smell danger: acquired associative representation of threat in the olfactory cortex. Front Behav Neurosci 8:98. CrossRef Medline

Li W, Luxenberg E, Parrish T, Gottfried JA (2006) Learning to smell the roses: experience-dependent neural plasticity in human piriform and orbitofrontal cortices. Neuron 52:1097-1108. CrossRef Medline

Lowry CA, Kay LM (2007) Chemical factors determine olfactory system beta oscillations in waking rats. J Neurophysiol 98:394-404. CrossRef Medline

Mandairon N, Poncelet J, Bensafi M, Didier A (2009) Humans and mice express similar olfactory preferences. PLoS One 4:e4209. CrossRef Medline

Martin C, Beshel J, Kay LM (2007) An olfacto-hippocampal network is dynamically involved in odor-discrimination learning. J Neurophysiol 98: 2196-2205. CrossRef Medline

Martinez-Marcos A (2009) On the organization of olfactory and vomeronasal cortices. Prog Neurobiol 87:21-30. CrossRef Medline

McGregor IS, Hargreaves GA, Apfelbach R, Hunt GE (2004) Neural correlates of cat odor-induced anxiety in rats: region-specific effects of the benzodiazepine midazolam. J Neurosci 24:4134-4144. CrossRef Medline

Mennella JA, Beauchamp GK (1997) The ontogeny of human flavor perception. In: Tasting and smelling: handbook of perception and cognition, Ed 2 (Beauchamp GK, Bartoshuk L, eds). San Diego: Academic.

Mennella JA, Moltz H (1988) Infanticide in rats: male strategy and female counter-strategy. Physiol Behav 42:19-28. CrossRef Medline

Mennella JA, Griffin CE, Beauchamp GK (2004) Flavor programming during infancy. Pediatrics 113:840-845. CrossRef Medline

Moriceau S, Sullivan RM (2004a) Unique neural circuitry for neonatal olfactory learning. J Neurosci 24:1182-1189. CrossRef Medline

Moriceau S, Sullivan RM (2004b) Corticosterone influences on Mammalian neonatal sensitive-period learning. Behav Neurosci 118:274-281. CrossRef Medline

Moriceau S, Sullivan RM (2006) Maternal presence serves as a switch between learning fear and attraction in infancy. Nat Neurosci 9:1004-1006. CrossRef Medline

Moriceau S, Roth TL, Okotoghaide T, Sullivan RM (2004) Corticosterone controls the developmental emergence of fear and amygdala function to predator odors in infant rat pups. Int J Dev Neurosci 22:415-422. CrossRef Medline

Moriceau S, Wilson DA, Levine S, Sullivan RM (2006) Dual circuitry for odor-shock conditioning during infancy: corticosterone switches between fear and attraction via amygdala. J Neurosci 26:6737-6748. CrossRef Medline

Moriceau S, Shionoya K, Jakubs K, Sullivan RM (2009) Early-life stress disrupts attachment learning: the role of amygdala corticosterone, locus ceruleus corticotropin releasing hormone, and olfactory bulb norepinephrine. J Neurosci 29:15745-15755. CrossRef Medline

Moriceau S, Roth TL, Sullivan RM (2010) Rodent model of infant attachment learning and stress. Dev Psychobiol 52:651-660. CrossRef Medline

Morrison FG, Dias BG, Ressler KJ (2015) Extinction reverses olfactory fearconditioned increases in neuron number and glomerular size. Proc Natl Acad Sci U S A 112:12846-12851. CrossRef Medline

Morrison GL, Fontaine CJ, Harley CW, Yuan Q (2013) A role for the anterior piriform cortex in early odor preference learning: evidence for multiple olfactory learning structures in the rat pup. J Neurophysiol 110: 141-152. CrossRef Medline

Mukherjee B, Harley CW, Yuan Q (2015) Learning-induced metaplasticity? Associative training for early odor preference learning down-regulates synapse-specific NMDA receptors via mGluR and calcineurin activation. Cereb Cortex. In press.

Murakami M, Kashiwadani H, Kirino Y, Mori K (2005) State-dependent sensory gating in olfactory cortex. Neuron 46:285-296. CrossRef Medline

Murakami T, Matsukawa M, Katsuyama N, Imada M, Aizawa S, Sato T (2012) Stress-related activities induced by predator odor may become indistinguishable by hinokitiol odor. Neuroreport 23:1071-1076. CrossRef Medline

Nacher J, Pham K, Gil-Fernandez V, McEwen BS (2004) Chronic restraint stress and chronic corticosterone treatment modulate differentially the expression of molecules related to structural plasticity in the adult rat piriform cortex. Neuroscience 126:503-509. CrossRef Medline

Pager J (1986) Neural correlates of odor-guided behaviors. Experientia 42: 250-256. CrossRef Medline

Pager J, Giachetti I, Holley A, Le Magnen J (1972) A selective control of olfactory bulb electrical activity in relation to food deprivation and satiety in rats. Physiol Behav 9:573-579. CrossRef Medline

Parma V, Bulgheroni M, Tirindelli R, Castiello U (2014) Facilitation of action planning in children with autism: the contribution of the maternal body odor. Brain Cogn 88:73-82. CrossRef Medline

Patin A, Pause BM (2015) Human amygdala activations during nasal chemoreception. Neuropsychologia 78:171-194. CrossRef Medline

Paxinos G, Watson C (1986) The rat brain in stereotaxic coordinates, compact Ed 6. New York: Academic.

Raineki C, Moriceau S, Sullivan RM (2010a) Developing a neurobehavioral animal model of infant attachment to an abusive caregiver. Biol Psychiatry 67:1137-1145. CrossRef Medline

Raineki C, Holman PJ, Debiec J, Bugg M, Beasley A, Sullivan RM (2010b) Functional emergence of the hippocampus in context fear learning in infant rats. Hippocampus 20:1037-1046. CrossRef Medline

Raineki C, Pickenhagen A, Roth TL, Babstock DM, McLean JH, Harley CW, Lucion AB, Sullivan RM (2010c) The neurobiology of infant maternal odor learning. Braz J Med Biol Res 43:914-919. CrossRef Medline

Raineki C, Sarro E, Rincón-Cortés M, Perry R, Boggs J, Holman CJ, Wilson DA, Sullivan RM (2015) Paradoxical neurobehavioral rescue by memories of early-life abuse: the safety signal value of odors learned during abusive attachment. Neuropsychopharmacology 40:906-914. CrossRef Medline

Rinberg D, Gelperin A (2006) Olfactory neuronal dynamics in behaving animals. Semin Cell Dev Biol 17:454-461. CrossRef Medline

Rinck F, Barkat-Defradas M, Chakirian A, Joussain P, Bourgeat F, Thévenet M, Rouby C, Bensafi M (2011) Ontogeny of odor liking during childhood and its relation to language development. Chem Senses 36:83-91. CrossRef Medline

Rincón-Cortés M, Barr GA, Mouly AM, Shionoya K, Nuñez BS, Sullivan RM (2015) Enduring good memories of infant trauma: rescue of adult neurobehavioral deficits via amygdala serotonin and corticosterone interaction. Proc Natl Acad Sci U S A 112:881-886. CrossRef Medline

Rolls ET, Critchley HD, Mason R, Wakeman EA (1996) Orbitofrontal cortex neurons: role in olfactory and visual association learning. J Neurophysiol 75:1970-1981. Medline

Root CM, Denny CA, Hen R, Axel R (2014) The participation of cortical amygdala in innate, odour-driven behaviour. Nature 515:269-273. CrossRef Medline

Roth TL, Sullivan RM (2005) Memory of early maltreatment: neonatal behavioral and neural correlates of maternal maltreatment within the context of classical conditioning. Biol Psychiatry 57:823-831. CrossRef Medline

Sadrian B, Wilson DA (2015) Optogenetic stimulation of lateral amygdala 
input to posterior piriform cortex modulates single-unit and ensemble odor processing. Front Neural Circuits 9:81. CrossRef Medline

Sarro EC, Wilson DA, Sullivan RM (2014) Maternal regulation of infant brain state. Curr Biol 24:1664-1669. CrossRef Medline

Schaal B (2014) Prenatal and postnatal human olfactory development: influences on cognition and behavior. In: Handbook of olfaction and gustation. R. L. Doty, ed. New York: Wiley.

Schiller D, Levy I, Niv Y, LeDoux JE, Phelps EA (2008) From fear to safety and back: reversal of fear in the human brain. J Neurosci 28:11517-11525. CrossRef Medline

Schmidt HJ, Beauchamp GK (1988) Adult-like odor preferences and aversions in three-year-old children. Child Dev 59:1136-1143. CrossRef Medline

Schoenbaum G, Chiba AA, Gallagher M (1999) Neural encoding in orbitofrontal cortex and basolateral amygdala during olfactory discrimination learning. J Neurosci 19:1876-1884. Medline

Sevelinges Y, Moriceau S, Holman P, Miner C, Muzny K, Gervais R, Mouly AM, Sullivan RM (2007) Enduring effects of infant memories: infant odor-shock conditioning attenuates amygdala activity and adult fear conditioning. Biol Psychiatry 62:1070-1079. CrossRef Medline

Sevelinges Y, Mouly AM, Raineki C, Moriceau S, Forest C, Sullivan RM (2011) Adult depression-like behavior, amygdala and olfactory cortex functions are restored by odor previously paired with shock during infant's sensitive period attachment learning. Dev Cogn Neurosci 1:77-87. CrossRef Medline

Shepherd GM (2006) Smell images and the flavour system in the human brain. Nature 444:316-321. CrossRef Medline

Singh PJ, Tobach E (1975) Olfactory bulbectomy and nursing behavior in rat pups (Wistar DAB). Dev Psychobiol 8:151-164. CrossRef Medline

Sullivan RM, Perry RE (2015) Mechanisms and functional implications of social buffering in infants: Lessons from animal models. Soc Neurosci 10:500-511. CrossRef Medline

Sullivan RM, Toubas P (1998) Clinical usefulness of maternal odor in newborns: soothing and feeding preparatory responses. Biol Neonate 74: 402-408. CrossRef Medline

Sullivan RM, Wilson DA (1991) Neural correlates of conditioned odor avoidance in infant rats. Behav Neurosci 105:307-312. CrossRef Medline

Sullivan RM, Wilson DA (1995) Dissociation of behavioral and neural correlates of early associative learning. Dev Psychobiol 28:213-219. CrossRef Medline

Sullivan RM, Wilson DA, Leon M (1989) Norepinephrine and learninginduced plasticity in infant rat olfactory system. J Neurosci 9:3998-4006. Medline

Sullivan RM, Wilson DA, Wong R, Correa A, Leon M (1990) Modified behavioral and olfactory bulb responses to maternal odors in preweanling rats. Brain Res Dev Brain Res 53:243-247. CrossRef Medline

Sullivan RM, Landers M, Yeaman B, Wilson DA (2000) Good memories of bad events in infancy. Nature 407:38-39. Medline

Sullivan R, Perry R, Sloan A, Kleinhaus K, Burtchen N (2011) Infant bond- ing and attachment to the caregiver: insights from basic and clinical science. Clin Perinatol 38:643-655. CrossRef Medline

Takahashi LK (1992) Ontogeny of behavioral inhibition induced by unfamiliar adult male conspecifics in preweanling rats. Physiol Behav 52: 493-498. CrossRef Medline

Takahashi LK (2014) Olfactory systems and neural circuits that modulate predator odor fear. Front Behav Neurosci 8:72. CrossRef Medline

Teicher MH, Blass EM (1977) First suckling response of the newborn albino rat: the roles of olfaction and amniotic fluid. Science 198:635-636. CrossRef Medline

Upton KJ, Sullivan RM (2010) Defining age limits of the sensitive period for attachment learning in rat pups. Dev Psychobiol 52:453-464. CrossRef Medline

Vanderwolf CH, Zibrowski EM, Wakarchuk D (2002) The ability of various chemicals to elicit olfactory beta-waves in the pyriform cortex of meadow voles (Microtus pennsylvanicus) and laboratory rats (Rattus norvegicus). Brain Res 924:151-158. CrossRef Medline

Varendi H, Porter RH (2001) Breast odour as the only maternal stimulus elicits crawling towards the odour source. Acta Paediatr 90:372-375. Medline

Wiedenmayer CP, Barr GA (2001a) Developmental changes in c-fos expression to an age-specific social stressor in infant rats. Behav Brain Res 126: 147-157. CrossRef Medline

Wiedenmayer CP, Barr GA (2001b) Developmental changes in responsivity to threat are stimulus-specific in rats. Dev Psychobiol 39:1-7. CrossRef Medline

Wiedenmayer CP, Magarinos AM, McEwen BS, Barr G (2003) Mother lowers glucocorticoid levels of preweaning rats after acute threat. Ann N Y Acad Sci 1008:304-307. CrossRef Medline

Wilson DA, Sullivan RM (2011) Cortical processing of odor objects. Neuron 72:506-519. CrossRef Medline

Wilson DA, Sullivan RM, Leon M (1987) Single-unit analysis of postnatal olfactory learning: modified olfactory bulb output response patterns to learned attractive odors. J Neurosci 7:3154-3162. Medline

Wilson DA, Kadohisa M, Fletcher ML (2006) Cortical contributions to olfaction: plasticity and perception. Semin Cell Dev Biol 17:462-470. CrossRef Medline

Xia CZ, Adjei S, Wesson DW (2015) Coding of odor stimulus features among secondary olfactory structures. J Neurophysiol 114:736-745. CrossRef Medline

Xu F, Greer CA, Shepherd GM (2000) Odor maps in the olfactory bulb. J Comp Neurol 422:489-495. CrossRef Medline

Yuan Q, Harley CW, Darby-King A, Neve RL, McLean JH (2003) Early odor preference learning in the rat: bidirectional effects of cAMP response element-binding protein (CREB) and mutant CREB support a causal role for phosphorylated CREB. J Neurosci 23:4760-4765. Medline

Yurgelun-Todd DA, Killgore WD (2006) Fear-related activity in the prefrontal cortex increases with age during adolescence: a preliminary fMRI study. Neurosci Lett 406:194-199. CrossRef Medline 